\title{
Hohenpeissenberg Photochemical Experiment (HOPE 2000): Measurements and photostationary state calculations of $\mathrm{OH}$ and peroxy radicals
}

\author{
G. M. Handisides ${ }^{1}$, C. Plass-Dülmer ${ }^{2}$, S. Gilge ${ }^{2}$, H. Bingemer ${ }^{1}$, and H. Berresheim ${ }^{2}$ \\ ${ }^{1}$ Institute for Meteorology and Geophysics, Frankfurt am Main, Germany \\ ${ }^{2}$ German Weather Service, Hohenpeissenberg, Germany
}

Received: 31 October 2002 - Published in Atmos. Chem. Phys. Discuss.: 16 December 2002

Revised: 15 July 2003 - Accepted: 25 August 2003 - Published: 1 October 2003

\begin{abstract}
Measurements of $\mathrm{OH}$, total peroxy radicals, nonmethane hydrocarbons (NMHCs) and various other trace gases were made at the Meteorological Observatory Hohenpeissenberg in June 2000. The data from an intensive measurement period characterised by high solar insolation (18-21 June) are analysed. The maximum midday $\mathrm{OH}$ concentration ranged between $4.5 \times 10^{6}$ molecules $\mathrm{cm}^{-3}$ and $7.4 \times 10^{6}$ molecules $\mathrm{cm}^{-3}$. The maximum total $\mathrm{RO}_{\mathrm{X}}\left(\mathrm{RO}_{\mathrm{X}}=\mathrm{OH}+\mathrm{RO}+\mathrm{HO}_{2}+\mathrm{RO}_{2}\right)$ mixing ratio increased from about 55 pptv on 18 June to nearly 70 pptv on 20 and 21 June. A total of 64 NMHCs, including isoprene and monoterpenes, were measured every 1 to 6 hours. The oxidation rate of the NMHCs by $\mathrm{OH}$ was calculated and reached a total of over $14 \times 10^{6}$ molecules $\mathrm{cm}^{-3} \mathrm{~s}^{-1}$ on two days. A simple photostationary state balance model was used to simulate the ambient $\mathrm{OH}$ and peroxy radical concentrations with the measured data as input. This approach was able to reproduce the main features of the diurnal profiles of both $\mathrm{OH}$ and peroxy radicals. The balance equations were used to test the effect of the assumptions made in this model. The results proved to be most sensitive to assumptions about the impact of unmeasured volatile organic compounds (VOC), e.g. formaldehyde (HCHO), and about the partitioning between $\mathrm{HO}_{2}$ and $\mathrm{RO}_{2}$. The measured $\mathrm{OH}$ concentration and peroxy radical mixing ratios were reproduced well by assuming the presence of $3 \mathrm{ppbv} \mathrm{HCHO}$ as a proxy for oxygenated hydrocarbons, and a $\mathrm{HO}_{2} / \mathrm{RO}_{2}$ ratio between $1: 1$ and 1:2. The most important source of $\mathrm{OH}$, and conversely the greatest sink for peroxy radicals, was the recycling of $\mathrm{HO}_{2}$ radicals to $\mathrm{OH}$. This reaction was responsible for the recycling of more than $45 \times 10^{6}$ molecules $\mathrm{cm}^{-3} \mathrm{~s}^{-1}$ on two days. The most important sink for $\mathrm{OH}$, and the largest source of peroxy radicals, was the oxidation of NMHCs, in particular, of isoprene and the monoterpenes.
\end{abstract}

Correspondence to: G. M. Handisides

(handisides@meteor.uni-frankfurt.de)

\section{Introduction}

Free radicals play an important role in the chemical selfcleansing of the atmosphere. The hydroxyl radical, $\mathrm{OH}$, is the main oxidising agent during daytime for many volatile organic compounds (VOCs), and other trace gases. Peroxy radicals $\left(\mathrm{RO}_{2}^{*}=\mathrm{HO}_{2}\right.$ and $\mathrm{RO}_{2}$, where $\mathrm{R}$ represents an organic group) are produced during many of these oxidation reactions. These peroxy radicals can react with $\mathrm{NO}$ to produce $\mathrm{NO}_{2}$, which leads to the production of ozone in the troposphere if the mixing ratio of NO exceeds 10-30 pptv (Atkinson, 2000).

The primary source of $\mathrm{OH}$ radicals in the troposphere is the photolysis of ozone and the subsequent reaction of the resulting $\mathrm{O}\left({ }^{1} \mathrm{D}\right)$ with water vapour:

$\mathrm{O}_{3}+\mathrm{h} v \stackrel{\lambda<335 \mathrm{~nm}}{\longrightarrow} \mathrm{O}_{2}+\mathrm{O}\left({ }^{1} \mathrm{D}\right)$

$\mathrm{O}\left({ }^{1} \mathrm{D}\right)+\mathrm{H}_{2} \mathrm{O} \longrightarrow \mathrm{OH}+\mathrm{OH}$

The $\mathrm{OH}$ radicals react with a large number of trace gases, including $\mathrm{CH}_{4}, \mathrm{CO}$ and non-methane hydrocarbons (NMHCs). These reactions typically result in the production of peroxy radicals:

$$
\begin{aligned}
& \mathrm{CO}+\mathrm{OH} \longrightarrow \mathrm{H}+\mathrm{CO}_{2} \\
& \mathrm{H}+\mathrm{O}_{2} \stackrel{\mathrm{M}}{\longrightarrow} \mathrm{HO}_{2} \\
& \mathrm{RH}+\mathrm{OH} \longrightarrow \mathrm{R}+\mathrm{H}_{2} \mathrm{O} \\
& \mathrm{R}+\mathrm{O}_{2} \stackrel{\mathrm{M}}{\longrightarrow} \mathrm{RO}_{2}
\end{aligned}
$$

Carbonyl compounds, e.g. $\mathrm{HCHO}$ and $\mathrm{CH}_{3} \mathrm{CHO}$, can be a significant source of peroxy radicals (e.g. Poppe et al., 1994; Carslaw et al., 2002) via photolysis and oxidation by $\mathrm{OH}$, e.g. for $\mathrm{HCHO}$ :

$$
\mathrm{HCHO}+\mathrm{h} v \stackrel{\lambda<337 \mathrm{~nm}}{\longrightarrow} \mathrm{H}+\mathrm{HCO}
$$


$\mathrm{HCHO}+\mathrm{OH} \longrightarrow \mathrm{H}_{2} \mathrm{O}+\mathrm{HCO}$

$\mathrm{HCO}+\mathrm{O}_{2} \longrightarrow \mathrm{HO}_{2}+\mathrm{CO}$

and by the conversion of the $\mathrm{H}$ atom generated in Reaction 7 following Reaction 4.

A further source of peroxy radicals is the oxidation of alkenes by the nitrate radical, $\mathrm{NO}_{3}$, and a small yield from the oxidation of alkenes by ozone. In the presence of high mixing ratios of biogenic alkenes, these reactions can be significant, although the reaction involving the $\mathrm{NO}_{3}$ radical is only of importance at night, as $\mathrm{NO}_{3}$ is rapidly photolysed during daytime.

The most important sink for $\mathrm{RO}_{2}^{*}$ radicals is the reaction with NO:

$$
\begin{aligned}
& \mathrm{RO}_{2}+\mathrm{NO} \longrightarrow \mathrm{RO}+\mathrm{NO}_{2} \\
& \mathrm{RO}+\mathrm{O}_{2} \longrightarrow \mathrm{R}^{\prime} \mathrm{O}+\mathrm{HO}_{2} \\
& \mathrm{HO}_{2}+\mathrm{NO} \longrightarrow \mathrm{OH}+\mathrm{NO}_{2} \\
& \mathrm{NO}_{2}+\mathrm{h} v \stackrel{\lambda<420 \mathrm{~nm}}{\longrightarrow} \mathrm{NO}+\mathrm{O}\left({ }^{3} \mathrm{P}\right) \\
& \mathrm{O}\left({ }^{3} \mathrm{P}\right)+\mathrm{O}_{2} \stackrel{\mathrm{M}}{\longrightarrow} \mathrm{O}_{3}
\end{aligned}
$$

where $\mathrm{R}^{\prime} \mathrm{O}$ in Reaction 11 is a carbonyl compound and $\mathrm{R}^{\prime}$ is equal to $\mathrm{R}$ except for the loss of one $\mathrm{H}$ atom. Reaction 12 represents an important secondary source of $\mathrm{OH}$ via recycling.

A number of combined field and modelling investigations of the $\mathrm{HO}_{\mathrm{X}}\left(\mathrm{HO}_{\mathrm{X}}=\mathrm{OH}+\mathrm{HO}_{2}\right)$ radical budget and of ozone formation have been undertaken to test our current understanding of photochemistry (e.g., Carslaw et al., 2001). In particular, concurrent measurements of both $\mathrm{OH}$ and $\mathrm{HO}_{2}$ have been made by several groups using the LIF method (e.g., Creasey et al., 2002; Tan et al., 2001; Kanaya et al., 2001; Abram et al., 2000; George et al., 1999; Holland et al., 1998). However, only a few campaigns have been reported in which measurements of both $\mathrm{OH}$ and $\mathrm{RO}_{\mathrm{X}}\left(\mathrm{RO}_{\mathrm{X}}=\mathrm{OH}+\mathrm{RO}+\mathrm{HO}_{2}+\mathrm{RO}_{\mathrm{X}}\right)$ radicals were made (e.g. Carslaw et al., 2002; Platt et al., 2002; Carslaw et al., 1999; Cantrell et al., 1996).

The Tropospheric $\mathrm{OH}$ Photochemistry Experiment (TOHPE) took place in the Rocky Mountains and included a broad range of measurement parameters, in particular OH (Tanner et al., 1997; Mount et al., 1997; Mather et al., 1997), $\mathrm{HO}_{2}$ (Mather et al., 1997) and $\mathrm{RO}_{\mathrm{x}}$ (Cantrell et al., 1997a). $\mathrm{OH}$ and $\mathrm{HO}_{2}$ concentrations were overestimated using a photostationary state model by $50 \%$ and by a factor of about 4, respectively (McKeen et al., 1997). Model calculations were made in which the concentrations of selected hydrocarbons were varied. The best agreement between the model results and the measurements of $\mathrm{OH}$ and $\mathrm{RO}_{2}^{*}$ were obtained by assuming the presence of a missing compound with the same chemical behaviour as $\beta$-pinene and a concentration 5 times higher than $\beta$-pinene.
The Program for Research on Oxidants: Photochemistry, Emissions and Transport (PROPHET) took place at a forested site in northern Michigan (Carroll et al., 2001). OH and $\mathrm{HO}_{2}$ measurements (Tan et al., 2001) were made in air characterised by high levels of isoprene and other biogenic hydrocarbons and low levels of $\mathrm{NO}$ and $\mathrm{NO}_{2}$. Model results using a tightly constrained photochemical point model underestimated $\mathrm{OH}$ by a factor of 2.7 , but were in good agreement with measured $\mathrm{HO}_{2}$.

Model results have tended to overestimate the $\mathrm{OH}$ concentration (Carslaw et al., 2002, 1999; George et al., 1999), with the PROPHET campaign representing a significant exception. Constraining the $\mathrm{HO}_{2}$ or $\mathrm{RO}_{\mathrm{x}}$ concentration using measured values tends to result in much better agreement between model results and measurements (e.g. George et al., 1999).

The aim of the Hohenpeissenberg Photochemistry Experiment (HOPE 2000) was to test our current understanding of free radical photochemistry in a rural environment using a photostationary radical balance model on the basis of measurements of both $\mathrm{OH}$ and $\mathrm{RO}_{\mathrm{X}}\left(\mathrm{RO}_{\mathrm{X}}\right.$ is the sum of the peroxy radicals, $\mathrm{OH}$ and the organic oxy radicals, $\mathrm{RO}_{\mathrm{X}}=\mathrm{OH}+\mathrm{RO}+\mathrm{HO}_{2}+\mathrm{RO}_{\mathrm{X}}$ ). The contributions of $\mathrm{OH}$ and $\mathrm{RO}$ to total $\mathrm{RO}_{\mathrm{X}}$ are sufficiently low that they can effectively be neglected, so that $\mathrm{RO}_{\mathrm{X}}$ is effectively equivalent to $\mathrm{RO}_{2}^{*}$. In the following paper this will be assumed to be the case and $\mathrm{RO}_{\mathrm{X}}$ will be used to refer to both $\mathrm{RO}_{\mathrm{X}}$ in the case of measurements and $\mathrm{RO}_{2}^{*}$ in the case of the model results. The short lifetimes of free radicals allow the use of a relatively simple box model, without having to consider transport processes. The model calculated the concentration of $\mathrm{OH}$ and of $\mathrm{RO}_{2}^{*}$ and was constrained in each case by the measured concentration of the other radical. The data set for the model consists of measurements of $\mathrm{OH}$, the sum of peroxy radicals $\left(\mathrm{RO}_{\mathrm{X}}\right)$, and with an extensive range of NMHCs and other trace gases relevant to $\mathrm{OH}$ and $\mathrm{RO}_{\mathrm{X}}$ chemistry. These were contributed by the Global Atmosphere Watch (WMO/GAW) monitoring programme at Hohenpeissenberg. Measurements of carbonyl compounds were not made during the HOPE 2000 campaign. However, the contributions of carbonyl compounds were considered and taken into account during the radical balance calculations.

\section{Experiment}

The Hohenpeissenberg Photochemistry Experiment (HOPE 2000) was conducted between 18 June and 6 July, 2000 at the Meteorological Observatory Hohenpeissenberg (MOHp). The observatory is both a meteorological monitoring and a Global Atmosphere Watch site operated by the German Weather Service (DWD). It is located in a rural agricultural and forested area approximately $40 \mathrm{~km}$ from the northern rim of the Alps at $980 \mathrm{~m}$ a.s.1. ( $47^{\circ} 48^{\prime} \mathrm{N}, 11^{\circ} 02^{\prime} \mathrm{E}$, see Fig. 1 ), and about $300-400 \mathrm{~m}$ above the surrounding countryside. 


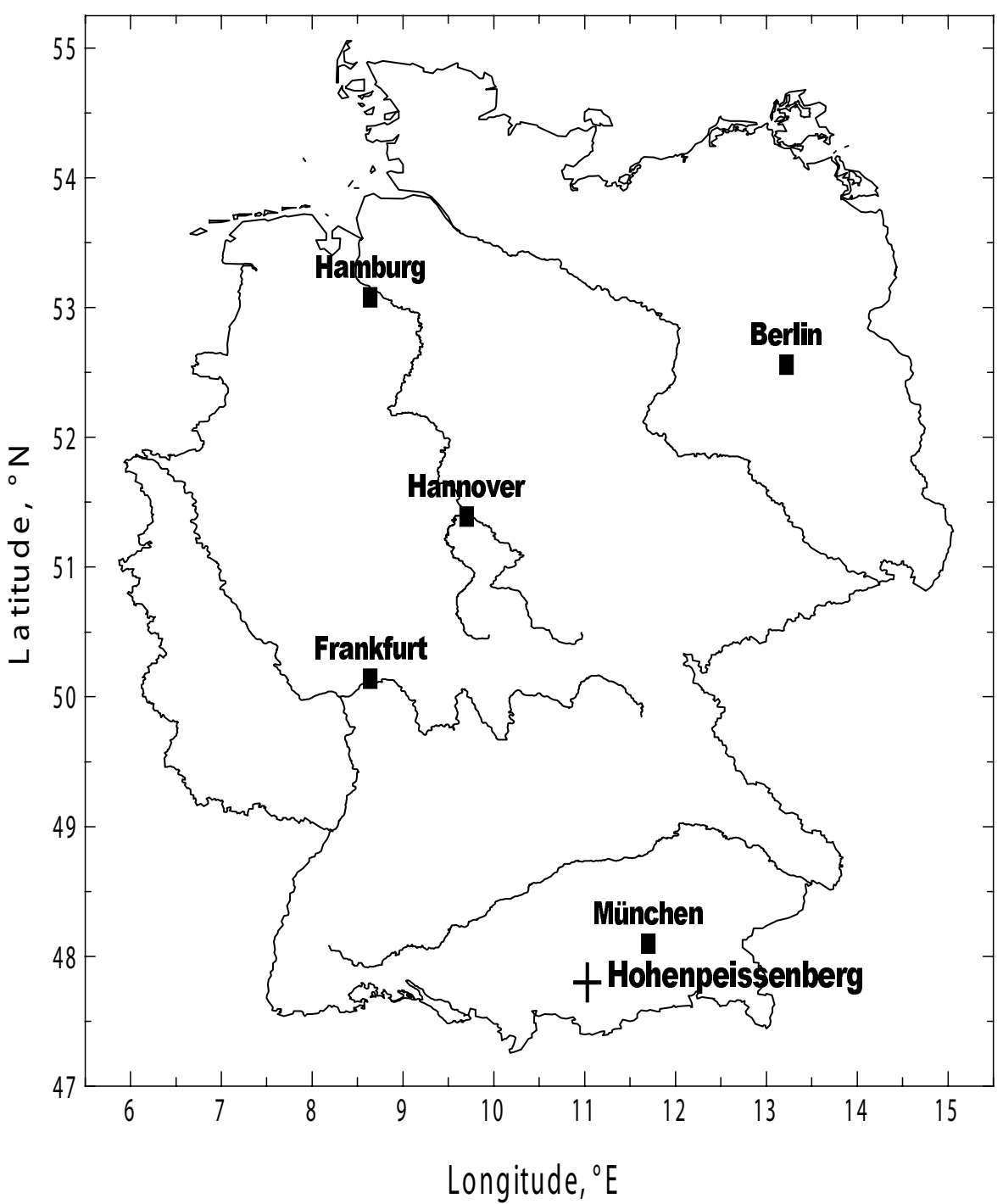

Fig. 1. Map of Germany showing the location of the Meteorological Observatory Hohenpeissenberg (975 m a.s.1.) in southern Bavaria.

Local noon occurs at 12:16CET. There are no significant industrial sources in the vicinity. The nearest city, Munich, is approximately $70 \mathrm{~km}$ to the northeast of the site.

The initial four day period of the campaign (18 to 21 June) was characterised by fine weather conditions, relatively high daytime temperatures (up to $27^{\circ} \mathrm{C}$ ) and intense photochemical activity associated with a high pressure system over central Europe. The wind was generally from the east during daytime, with relatively light winds of under $4 \mathrm{~m} \mathrm{~s}^{-1}$. This episode was the focus of the intensive series of measurements presented here.

The inlets for all trace gas monitoring instruments were located within $7 \mathrm{~m}$ of each other on the roof of a container tower at approximately $10 \mathrm{~m}$ above ground level, which is the height of the nearby trees. Reagent gases such as NO, $\mathrm{NO}_{2}, \mathrm{CO}, \mathrm{SO}_{2}$ and propane were exhausted through a tub- ing line about $50 \mathrm{~m}$ south of the measurement site. The local wind direction during HOPE 2000 was only occasionally from this sector and the time series for these trace gases did not show any indications of exhaust contamination. Meteorological measurements were made at a horizontal distance of $50 \mathrm{~m}$ from the container tower. Wind measurements were made on top of a $40 \mathrm{~m}$ mast.

The instrumentation used during HOPE, with the exception of the standard meteorological instrumentation, is summarised in Table 1. The photolysis rates of $\mathrm{NO}_{2}$ and ozone, $\mathrm{j}_{\mathrm{NO}_{2}}$ and $\mathrm{j}_{\mathrm{O}^{1} \mathrm{D}}$, respectively, were both measured using two filter-radiometers $(2 \pi \mathrm{sr})$, facing up and down, and thus providing $4 \pi$ sr photolysis rates. Nitrogen oxides were measured by $\mathrm{NO}-\mathrm{O}_{3}$ chemiluminescence analysers ( 2 systems, ECO Physics CLD $770 \mathrm{AL}$ ppt). $\mathrm{NO}_{2}$ and $\mathrm{NO}_{\mathrm{y}}$ are converted into NO prior to measurement by a photolytic converter 
Table 1. Summary of instrumentation used during HOPE, in June and July 2000

\begin{tabular}{|c|c|c|c|c|}
\hline Component & Instrument & Measurement method & $\begin{array}{c}\text { Signal } \\
\text { Integration Period }\end{array}$ & Accuracy $^{a}$ \\
\hline \multicolumn{5}{|l|}{ TRACE GASES } \\
\hline $\mathrm{OH}$ & DWD-CIMS & Chemical ionisation mass spectrometry & $5 \mathrm{~min}$ & see text \\
\hline $\mathrm{RO}_{\mathrm{X}}$ & IMG-CA & Chemical amplification & $10 \mathrm{~min}$. & see text \\
\hline Ozone & Thermo Instr./Dasibi & UV absorption & $1 \mathrm{~min}$ & $4 \%, 0.5 \mathrm{ppbv}$ \\
\hline NO & EcoPhysics & Chemoluminescence Detector (CLD) & $3 \mathrm{~min}$ & $5 \%, 15 \mathrm{pptv}$ \\
\hline $\mathrm{NO}_{2}$ & EcoPhysics & CLD with photolytic converter & $3 \mathrm{~min}$ & $6 \%, 30 \mathrm{pptv}$ \\
\hline $\mathrm{NO}_{\mathrm{y}}$ & EcoPhysics & CLD with gold converter & $4 \min$ & $9 \%, 50 \mathrm{pptv}$ \\
\hline $\mathrm{SO}_{2}$ & Thermo Instruments & UV fluorescence & $1 \mathrm{~min}$ & $5 \%, 50 \mathrm{pptv}$ \\
\hline $\mathrm{H}_{2} \mathrm{O}_{2}, \mathrm{ROOH}$ & AeroLaser/Custom built & Enzyme Catalysed Fluorescence & $1 \mathrm{~min}$ & $9 \%, 100$ pptv \\
\hline $\mathrm{CO}$ & Thermo Instruments & IR absorption with gas filter correlation & $20 \mathrm{~min}$ & $5 \%, 5 \mathrm{ppbv}$ \\
\hline $\mathrm{C}_{2}-\mathrm{C}_{8} \mathrm{HC}$ & Varian/Custom built & GC/FID & $15 \min ^{b}$ & see text \\
\hline $\mathrm{C}_{5}-\mathrm{C}_{13}$ & Varian/Custom built & GC/MS/FID & $20 \min ^{c}$ & see text \\
\hline \multicolumn{5}{|l|}{ RADIATION } \\
\hline Global radiation & Kipp \& Zonen CM11 & Moll thermopile & $1 \mathrm{~min}$ & $3 \%$ \\
\hline $\mathrm{j}_{\mathrm{O}^{1} \mathrm{D}}$ & MetCon, Glashütten & filter radiometer & $1 \mathrm{~min}$ & $25 \%$ \\
\hline $\mathrm{j}_{\mathrm{NO}_{2}}$ & MetCon, Glashütten & filter radiometer & $1 \mathrm{~min}$ & $15 \%$ \\
\hline
\end{tabular}

${ }^{a}$ For each measurement the accuracy is determined by the larger of the two values.

${ }^{b}$ Sample Frequency: every $75 \mathrm{~min}-6 \mathrm{~h}$

${ }^{c}$ Sample Frequency: every $60 \mathrm{~min}-6 \mathrm{~h}$.

(ECO Physics PLC 760) and a gold converter with added $\mathrm{CO}$ built at MOHp, respectively. A high volume stainless steel inlet line is used for $\mathrm{NO}_{\mathrm{x}}$ and a PFA inlet line for $\mathrm{NO}_{\mathrm{y}}$. Calibration and zero gas measurements are carried out every second day as part of a detailed QA/QC procedure. Between 1998 and 2002, the $\mathrm{NO}, \mathrm{NO}_{2}$ and $\mathrm{NO}_{\mathrm{y}}$ measurements were checked in three informal intercomparison experiments (May 1998: NO, with Juelich Research Centre; December 1999 and August 2002: NO, $\mathrm{NO}_{2}, \mathrm{NO}_{\mathrm{y}}$, with German National Aerospace Centre, DLR). The agreement between the participating instruments was found to be better than the corresponding accuracy range (S. Gilge, unpublished results). The accuracy estimates listed in Table 1 take into account uncertainties in the calibration gas standard concentration, the calibration gas dilution system, the efficiency of the converters, the reproducibility of the measurements, and inlet line losses of $\mathrm{NO}_{\mathrm{y}}$ in the range of $5 \%$. For individual measurements, this leads to an accuracy of $5.2 \%$ (or $15 \mathrm{pptv}$ ) for NO, $5.6 \%$ (or $30 \mathrm{pptv}$ ) for $\mathrm{NO}_{2}$, and $9 \%$ (or $50 \mathrm{pptv}$ ) for $\mathrm{NO}_{\mathrm{y}}$. The lower detection limits are given in brackets. During the HOPE 2000 campaign, nighttime NO mixing ratios were below the detection limit of 15 pptv for individual measurements with a 3 min signal integration period (see Sect. 3). NO mixing ratios of $6 \pm 4$ pptv were determined for integration periods of one hour. Since a small positive offset due to alkene-ozone reactions in the chemiluminescence detector (with pre-reaction chamber) cannot be excluded, an upper limit for the nighttime NO mixing ratio of 6 pptv is assumed during HOPE 2000.

Atmospheric $\mathrm{OH}$ concentrations were measured using the selected ion/chemical ionisation mass spectrometry (SI/CIMS) technique as described by Berresheim et al. (2000). The measurement principle is based on three major steps:

1. Titration of the $\mathrm{OH}$ in the sample air by excess ${ }^{34} \mathrm{SO}_{2}$ to produce the heavy isotope $\mathrm{H}_{2}^{34} \mathrm{SO}_{4}$,

2. Charge transfer of the $\mathrm{H}_{2}^{34} \mathrm{SO}_{4}$ with $\mathrm{NO}_{3}^{-}$ions (which are selectively formed in a separate purified air flow by alpha bombardment from a radioactive ${ }^{241} \mathrm{Am}$ source) resulting in $\mathrm{H}^{34} \mathrm{SO}_{4}^{-}$product ions, and

3. Measurement of the $\mathrm{H}^{34} \mathrm{SO}_{4}^{-} / \mathrm{NO}_{3}^{-}$ion ratio by MS after transfer of the ions into the vacuum region. To measure the background signal, excess high purity propane is added to the sample air $/ \mathrm{SO}_{2}$ mixture to scavenge the $\mathrm{OH}$ radicals by reaction with the propane instead of $\mathrm{SO}_{2}$. The $\mathrm{OH}$ concentration is determined from the $\mathrm{H}^{34} \mathrm{SO}_{4}^{-} / \mathrm{NO}_{3}^{-}$signal ratio using a calibration factor, $\mathrm{F}$, which is determined each day. Calibration is based on UV-photolysis ( $\lambda=185 \mathrm{~nm}$ ) of ambient air water vapour in front of the sample tube. This yields $\mathrm{OH}$ concentrations in the $10^{7}-10^{8}$ molecule $\mathrm{cm}^{-3}$ range. The $\mathrm{OH}$ concentration is calculated based on the known $\mathrm{H}_{2} \mathrm{O}$ absorption cross section (Cantrell et al., 1997b), 
concurrent measurements of $\left[\mathrm{H}_{2} \mathrm{O}\right]$ using a chilled mirror dewpoint hygrometer (Michell Instruments), and the photon flux in the photolysis zone, which is measured using calibrated (solar-blind) phototubes (Hamamatsu).

The impact of $\mathrm{OH}$ losses on the surfaces of the containers can be considered to be negligible for the $\mathrm{OH}$ measurements presented here. This was tested by alternating the position of the $\mathrm{OH}$ intake above the roof surface between 40 and $160 \mathrm{~cm}$ (the position during measurement is $50 \mathrm{~cm}$ ). The difference did not exceed the range of uncertainty of $10 \%$ for wind speeds varying between 0 and $6 \mathrm{~m} \mathrm{~s}^{-1}$. OH concentrations measured during the HOPE campaign were corrected for errors resulting from chemical reactions within the measurement system. The correction followed an iterative chemical model previously described by Berresheim et al. (2000) and Tanner et al. (1997). Corresponding corrections were calculated for chemical reactions in both the sample inlet and the $\mathrm{OH}$ titration zone using measured ambient air concentrations of $\mathrm{NO}, \mathrm{NO}_{2}, \mathrm{CO}$ and NMHCs. Depending on the concentrations of these compounds, the resulting total corrections ranged from $15 \%$ to $35 \%$. Taking these corrections into account, the overall $2 \sigma$ precision, accuracy, and detection limit of the $\mathrm{OH}$ measurements with 5 min signal integration during the HOPE campaign were $31 \%, 39 \%$, and $4 \times 10^{5}$ molecule $\mathrm{cm}^{-3}$, respectively.

The mixing ratio of the peroxy radicals $\left(\mathrm{RO}_{\mathrm{X}}\right)$ was measured using a peroxy radical chemical amplifier (CA) built by Handisides (2001). The peroxy radical chemical amplifier technique (Hastie et al., 1991; Cantrell et al., 1984) has been used in a large number of campaigns (e.g. Platt et al., 2002; Carslaw et al., 2002; Monks et al., 1996; Cantrell et al., 1996). In a recent field campaign (Platt et al., 2002), it was shown to compare well with direct $\mathrm{RO}_{\mathrm{X}}$ measurements made using Matrix Isolation/Electron Spin Resonance (MIESR) (Mihelcic et al., 1990). The design of the instrument used in HOPE 2000 is essentially identical to that of the instrument described by Hastie et al. (1991). The technique relies on a chain reaction involving peroxy radicals, $\mathrm{OH}$ and added $\mathrm{NO}$ and $\mathrm{CO}$, in which $\mathrm{NO}$ is oxidised to $\mathrm{NO}_{2}$. The chain reaction results in the production of $n$ molecules of $\mathrm{NO}_{2}$ for each peroxy radical, where $n$ is the length of the chain reaction and represents the signal amplification. During HOPE 2000, the value of $n$ obtained by calibration in dry air exceeded 160 . The reaction product $\mathrm{NO}_{2}$ is subsequently detected via its reaction with luminol using a liquid phase chemiluminescence detector. The amplification is modulated to allow the effect of ambient $\mathrm{NO}_{2}$ to be accounted for (see Hastie et al., 1991). PFA Teflon tubing with $6.35 \mathrm{~mm}(1 / 4$ ") o.d. and $4.83 \mathrm{~mm}$ (0.190") i.d. was used for the intake and all subsequent tubing in contact with the air sample. The distance between the addition points for $\mathrm{CO}$ was $1.6 \mathrm{~m}$ (the reaction tube) and the length of tubing between the second downflow addition point and the $\mathrm{NO}_{2}$ detector was $10 \mathrm{~m}$. The flow rate of ambient air through the system was $1.611 \mathrm{~min}^{-1}$ resulting in a total re- action time in the reaction tube of $0.66 \mathrm{~s}$. Radical calibration was performed using the photolysis of water at $185 \mathrm{~nm}$ generated by a PenRay mercury lamp (Schultz et al., 1995).

The CA technique has been found to be sensitive to the relative humidity in the sample air (Reichert et al., 2003; Reichert, 2000; Mihele and Hastie, 2000; Mihele et al., 1999; Mihele and Hastie, 1998). The CA measurements were corrected for this effect using a parametrisation of the data of Mihele and Hastie (2000), which were obtained using a CA with a Teflon inlet and similar operating parameters to that of the CA used here. Unpublished measurements made at the Max Planck Institute for Chemistry in Mainz (Thomas Klüpfel, personal communication) using a Teflon inlet showed a nearly identical response of the chemical amplification factor with respect to water to that observed by Mihele and Hastie (2000). Investigations using a different experimental technique and with an inlet made from plexiglass by Reichert (2000) (see also Reichert et al., 2003) found a much greater sensitivity to water vapour. The interpretation of the various studies is complicated by the fact that Reichert used a different material for the inlet, and a different experimental technique to measure the water effect. Reichert et al. (2003) suggest that the water effect is not solely due to wall loss but is due to reactions involving water complexes and $\mathrm{CO}$ or NO. They use a model to reproduce both the measurements of Reichert et al. and of Mihele and Hastie (1998). The model results help to validate the data of Mihele and Hastie (2000) for a chemical amplifier with similar inlet parameters to the chemical amplifier used during HOPE. Further studies are definitely required to characterise the effect of moisture more accurately and to determine its cause, and further measurements using the chemical amplifier most definitely require the water dependency to be determined directly. The accuracy of the measurements is about $\pm 60 \%$ at $50 \%$ relative humidity and is better when the air is drier. The data from the HOPE 2000 campaign presented here were measured at relative humidities between 25 and 50\%. The average 2- $\sigma$ detection limit was about 6 pptv at nighttime and increased to 9 pptv during the day.

Ambient $\mathrm{C}_{2}-\mathrm{C}_{10} \mathrm{NMHC}$ mixing ratios were measured online using two GC-systems operating simultaneously. During the period from 17 to 20 June, measurements of 64 species (see Table 3) were made every one to three hours during daytime. Both GCs share a common intake system in which ambient air is continuously flushed through a $10 \mathrm{~m}$ long, $4 \mathrm{~cm}$ i.d. glass tube (Duran, Schott Glasswerke, Mainz, Germany) at a flow rate of $1 \mathrm{~m}^{3} \mathrm{~min}^{-1}$ using a fan installed at the downstream end of the tube. Samples were transferred to each GC system from the centre of the air inlet flow through a silica-lined stainless steel tube $(1 \mathrm{~m}, 1 / 8$ " o.d., SILCOSTEEL, Restek Corp., Bellefonte, PA, USA).

The first GC system (GC-1, Varian $3600 \mathrm{CX}$ ) is used to detect light NMHCs $\left(\mathrm{C}_{2}-\mathrm{C}_{8}\right)$ and is described in detail in Plass-Dülmer et al. (2002). Ambient air samples (typically $750 \mathrm{~cm}^{3}$ ) are passed through heated stainless steel tubes 
serving as an effective ozone trap and a Nafion dryer for water vapour removal before the NMHC compounds are cryogenically trapped on glass beads cooled to $85 \mathrm{~K}$. After cryotrapping, the sample is desorbed at $473 \mathrm{~K}$ onto an $\mathrm{Al}_{2} \mathrm{O}_{3} / \mathrm{KCl} \mathrm{GC}$ column $(50 \mathrm{~m}, 0.53 \mathrm{~mm}$ i.d.). Following chromatographic separation, the individual compounds are detected by a flame ionisation detector (FID).

The second system (GC-2, Varian 3400CX) is optimised for the detection of $\mathrm{C}_{5}-\mathrm{C}_{13}$ NMHCs including isoprene and monoterpenes, and is similar to systems that have been successfully used by other groups for measuring these compounds (Helmig et al., 1998; Goldan et al., 1995; Riemer et al., 1994). Its main components are an ozone scrubber, an adsorption trap, a cryo-focussing unit, a gas chromatograph and a FID/MS detector. An air sample is taken from the main intake line at a flow rate of $50-80 \mathrm{ml} \mathrm{min}^{-1}$ and passes through a glass fibre filter impregnated with $\mathrm{Na}_{2} \mathrm{O}_{3} \mathrm{~S}_{2}$ to remove ozone (Helmig et al., 1998). In a sample preconcentration trap ( $1 / 8$ " o.d. and $30 \mathrm{~cm}$ length, SPT, Varian Inc.) NMHCs are adsorbed onto Carbopack B (40/60 mesh, Supelco Inc.) at $303 \mathrm{~K}$. The sample is desorbed at $503 \mathrm{~K}$ in a helium carrier gas flow of $30 \mathrm{ml} \mathrm{min}^{-1}$, and re-focussed again at $77 \mathrm{~K}$ in a silcosteel capillary $(0.28 \mathrm{~mm}$ i.d., $20 \mathrm{~cm})$. After desorption at $453 \mathrm{~K}$, NMHC are injected onto a BPX5 column $(50 \mathrm{~m}, 0.22 \mathrm{~mm}$ i.d.) in a helium carrier gas flow of $1.8 \mathrm{ml} \mathrm{min}^{-1}$. All materials in contact with the sample gas flow have inert surfaces, e.g. silcosteel, fused silica, and PTFE, and the Valco multiport valves (423 K, VICI CH) are made of stainless steel and Valcon-E. Chromatographic separation is achieved by using a temperature programme with an initial isothermal phase $(283 \mathrm{~K}, 10 \mathrm{~min})$ followed by a temperature ramp of $6 \mathrm{~K} / \mathrm{min}$ to $511 \mathrm{~K}$. The column effluent is split to an FID and an ion trap mass spectrometer (ITMS, Varian) at a fixed ratio of approximately $4: 1$. Quantification is based on the integration of selected mass peaks of characteristic fragment ions such as $\mathrm{m} / \mathrm{z}=136$ for some of the terpene compounds, and measurements of different calibration gas mixtures on a regular basis. By using characteristic mass chromatograms for quantification, the technique is basically a two-dimensional GC technique with significantly improved compound identification and quantification capabilities compared to a conventional one-dimensional GC.

A detailed quality assurance and quality control procedure has been developed for GC-2 similar to that described by Plass-Dülmer et al. (2002) for the measurements of light NMHC. It includes a thorough characterisation and optimisation of the system combined with frequent checks of the system's performance by measurements of standards, reference gases and zero gas. The monoterpenes are the most difficult of the $\mathrm{C}_{5}-\mathrm{C}_{13} \mathrm{NMHC}$ to measure for the following reasons: (1) they are highly reactive towards other constituents of air, especially ozone, (2) they may be subject to rearrangement reactions during concentration and thermal desorption, and (3) compounds with relatively low vapour pressures, e.g. 1,8cineol, may partially be lost by adsorption on surfaces. The
GC system used during the HOPE campaign has been thoroughly tested by direct measurements of individual monoterpenes and a terpene mixture (12 different monoterpenes at approximately $10 \mathrm{ppbv}$ in $\mathrm{N}_{2}$ ), and by standard addition measurements. The latter involved adding a small amount of an individual terpene or a terpene mixture to ambient air just in front of the silcosteel sample line. Artefacts arising from the various error sources outlined above were observed for several terpenes, however, they did not generally exceed $30 \%$ (see the corresponding accuracies in Table 3). Sabinene showed substantial decomposition and its measurement was estimated to have an uncertainty of $60 \%$. Products of the decomposition of sabinene in the analytical system were identified as p-cymene, $\alpha$ - and $\gamma$-terpinene. For this reason, and due to their low concentrations, the measurements of ambient $\alpha$ - and $\gamma$-terpinene were considered to have an uncertainty of $100 \%$ and $50 \%$, respectively. Consequently, $\alpha$-terpinene data were discarded from the HOPE 2000 data set. Overall, the accuracies $(2-\sigma)$ of most of the analysed NMHCs are better than $20 \%$ or a few pptv (Table 3 ). Detection limits are generally less than $10 \mathrm{pptv}$, and for the majority of compounds lie below 1-3 pptv.

$\mathrm{C}_{5}-\mathrm{C}_{8}$ hydrocarbons are measured by both $\mathrm{GC}$ systems. As part of the quality control procedure, the concentrations of several compounds measured by both systems, including isoprene, have been compared and the measurements agreed within the respective uncertainty ranges for both systems. The measurement results presented in this paper represent the $\mathrm{C}_{5}-\mathrm{C}_{13}$ mixing ratios measured by the GC-2 system and the corresponding mixing ratios for $\mathrm{C}_{2}-\mathrm{C}_{4}$ hydrocarbons from the GC-1 system interpolated temporally to the corresponding measurement times of the GC-2 measurements. This procedure was chosen since isoprene and monoterpenes (both measured by GC-2) had the largest influence on the concentrations of $\mathrm{OH}$ and $\mathrm{RO}_{\mathrm{X}}$.

\section{Measurement Results}

The results from the measurements during the intensive phase, 18 to 21 June, 2000, are presented in Figs. 2 to 4. The $\mathrm{OH}$ concentrations and the mixing ratios of $\mathrm{RO}_{\mathrm{X}}$, ozone, $\mathrm{NO}, \mathrm{NO}_{2}, \mathrm{H}_{2} \mathrm{O}_{2}, \mathrm{ROOH}, \mathrm{CO}$ and $\mathrm{SO}_{2}$ are shown in Fig. 2. Figure 3 shows the most important meteorological parameters for the same time interval. The mixing ratios of the most relevant NMHCs or groups of NMHCs are shown in Fig. 4. The maximum daily temperature exceeded $25^{\circ} \mathrm{C}$ on each day except for 18 June. Clear skies associated with synoptic high pressure conditions resulted in intense insolation and strong photochemical activity on each of the four days. Consequently, the profiles of $\mathrm{O}_{3}, \mathrm{RO}_{\mathrm{X}}, \mathrm{OH}, \mathrm{NO}$, isoprene and the terpenes all exhibit a strong diurnal behaviour. At nighttime, the station was situated above the boundary layer, so that ozone mixing ratios typically remained above 50 ppbv, and $\mathrm{NO}_{2}$ mixing ratios below 2 ppbv. 


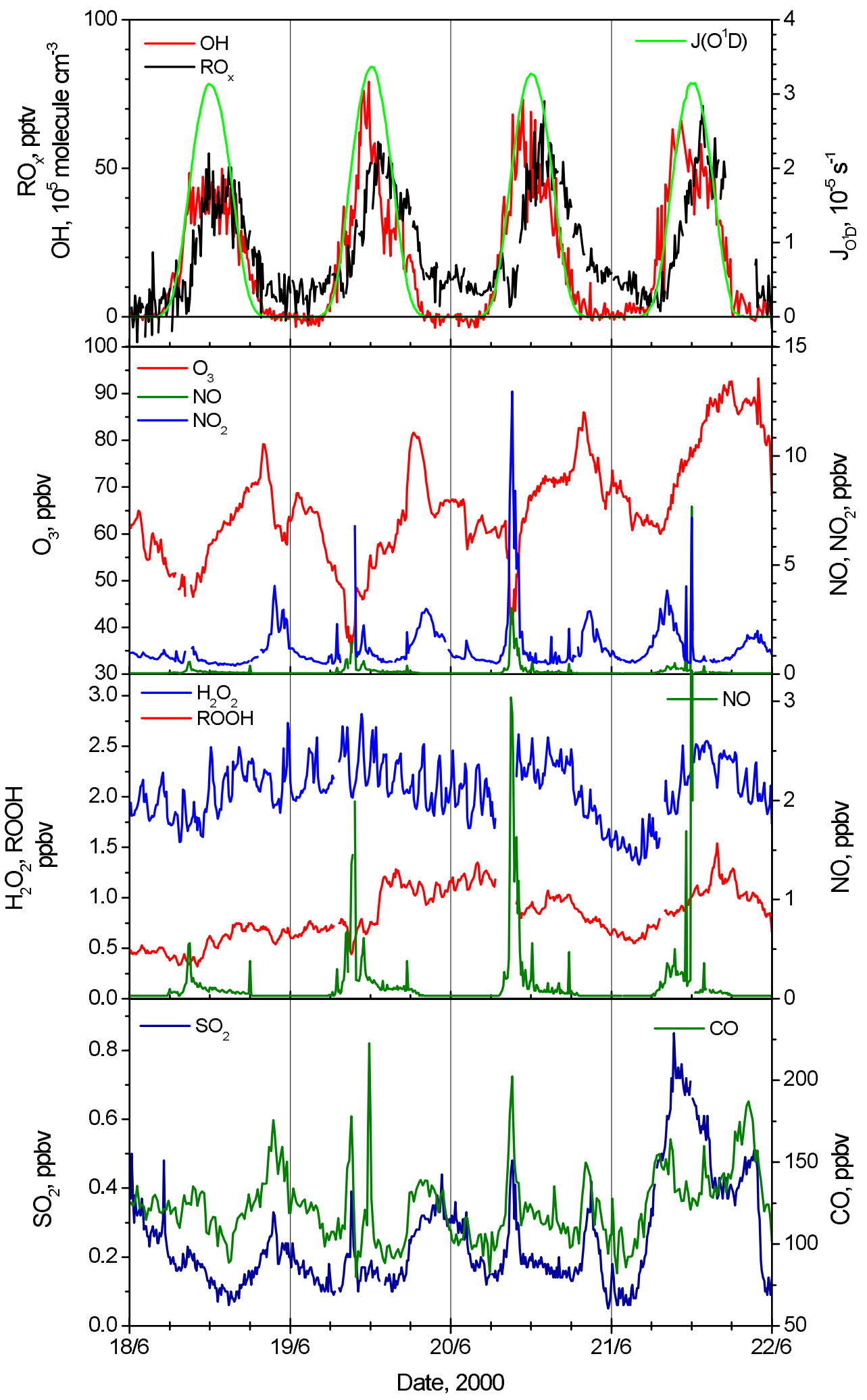

Fig. 2. Concentration of $\mathrm{OH}$ and mixing ratios of $\mathrm{RO}_{\mathrm{X}}$, ozone, $\mathrm{NO}, \mathrm{NO}_{2}, \mathrm{H}_{2} \mathrm{O}_{2}, \mathrm{ROOH}, \mathrm{CO}$ and $\mathrm{SO}_{2}$ measured at Hohenpeissenberg during the period 18 to 21 June, 2000. Data gaps are due to instrument calibration. The NO mixing ratio is included in two different panels at different scales (the peak NO mixing ratios are cut off in the lower panel). 


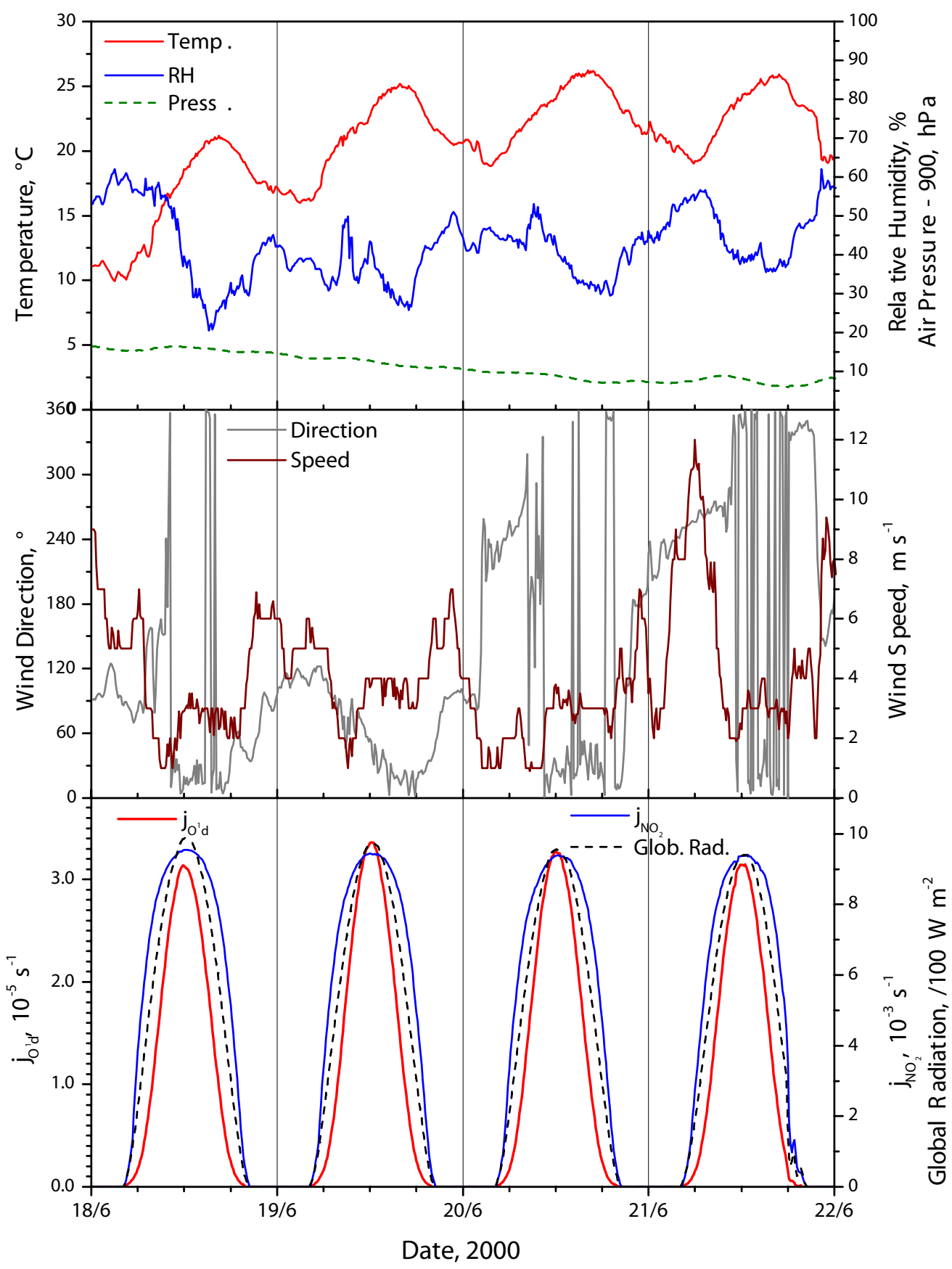

Fig. 3. Meteorological parameters at Hohenpeissenberg during the period 18 to 21 June, 2000.

The diurnal profiles of several trace gases provided evidence of significant vertical air mass transport between about 8:00 and 11:00 CET on each of the four days considered. During these events, air arriving at the measurement site due to convective lifting of the boundary layer was enriched in a number of trace gases with surface sources. This occurred most obviously on June 19 and 20, as shown by the corresponding mixing ratios of $\mathrm{NO}$ and $\mathrm{NO}_{2}$, some of the NMHCs, especially the biogenic terpenes and isoprene, and
- to a lesser extent - of $\mathrm{CO}$ and $\mathrm{SO}_{2}$. A corresponding dip in the $\mathrm{O}_{3}$ mixing ratio can be attributed to titration of $\mathrm{O}_{3}$ at the elevated NO mixing ratios and to $\mathrm{O}_{3}$ deposition. This interpretation is further supported by a corresponding increase in relative humidity on most days and the minimum in horizontal wind velocities on all days except 21 June (see Fig. 3). 


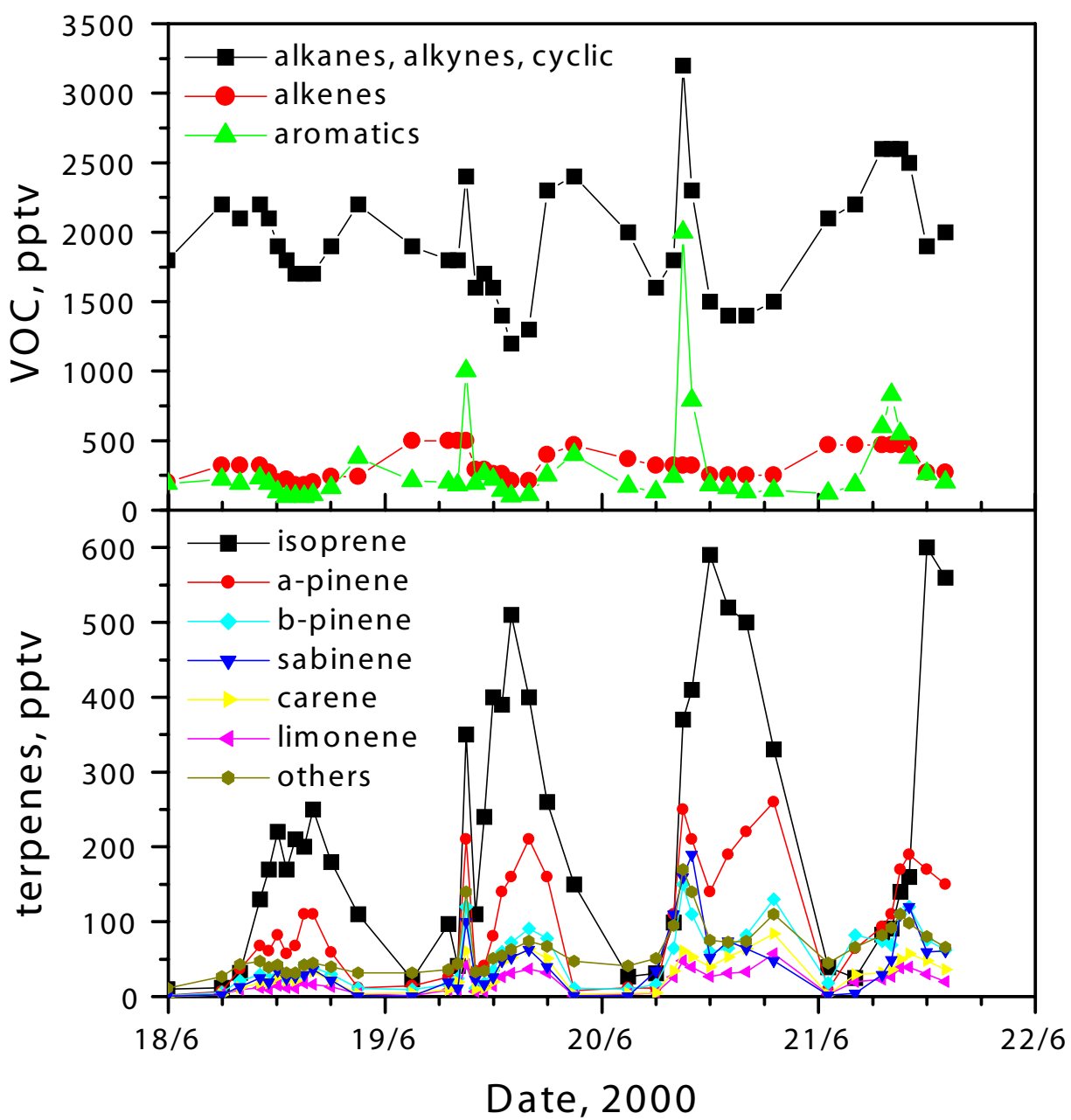

Fig. 4. Mixing ratios for various groups of NMHCs at Hohenpeissenberg during the period 18 to 21 June, 2000. The group labelled alkenes in the upper panel includes neither isoprene nor the terpenes.

During some evenings, peaks in the mixing ratios of several trace gases were observed in conjunction with changes in wind speed and direction. These represent a deviation from their respective diurnal profiles and suggest that large scale advection of polluted air masses occurred after sunset. The mixing ratios of $\mathrm{O}_{3}, \mathrm{SO}_{2}, \mathrm{CO}$ and $\mathrm{NO}_{2}$ all showed pronounced peaks between about 18:00 and 22:00 CET. The $\mathrm{O}_{3}$ mixing ratios always increased first, and later dropped again at the same time as the $\mathrm{NO}_{2}$ mixing ratio increased.

The $\mathrm{OH}$ concentration reached a maximum between 09:00 and 12:00CET (corresponds to 8:44 and 11:44 true local time, respectively) and generally dropped to below the detection limit of $4 \times 10^{5} \mathrm{~cm}^{-3}$ after 19:00-20:00 CET in the evening. On 19 and $20 \mathrm{June}, \mathrm{OH}$ reached maximum daytime concentrations of $7-8 \times 10^{6} \mathrm{~cm}^{3}$. As can be seen in the upper panel of Fig. 2, the shape of the diurnal profile of the $\mathrm{OH}$ concentration was similar to that of $\mathrm{j}_{\mathrm{O}^{1} \mathrm{D}}$ in the early morning and late afternoon on all days. However, the two profiles deviated considerably around local midday.
Maximum $\mathrm{RO}_{\mathrm{X}}$ mixing ratios occurred at around 14:00 CET and rose from about $55 \mathrm{pptv}$ on the 18th to around 70 pptv on both 20 and 21 June (Fig. 2). These levels are somewhat higher than some recent studies (e.g. Platt et al., 2002; Tan et al., 2001), however they lie within the range reported in the literature (e.g., 300 pptv reported by Cantrell et al., 1993). Most previously reported $\mathrm{RO}_{\mathrm{X}}$ measurements made using the chemical amplifier were not corrected for the effect of water vapour, so that the actual mixing ratios would be higher than the reported values. Levels of up to $10 \mathrm{pptv}$ $\mathrm{RO}_{\mathrm{X}}$ were observed at night, and were probably caused by enhanced night-time oxidation of NMHC by the nitrate radical and by $\mathrm{O}_{3}$, and the slow loss rate of the peroxy radicals in the absence of NO. The reaction rate with $\mathrm{NO}_{3}$ and $\mathrm{O}_{3}$ is much faster for secondary alkenes, such as isoprene and the terpenes, than for other alkenes and other NMHCs (Atkinson, 1997). Although no $\mathrm{NO}_{3}$ measurements were available, alkene measurements showed that concentrations of a few pptv to $150 \mathrm{pptv}$ of individual biogenic NMHCs were present 


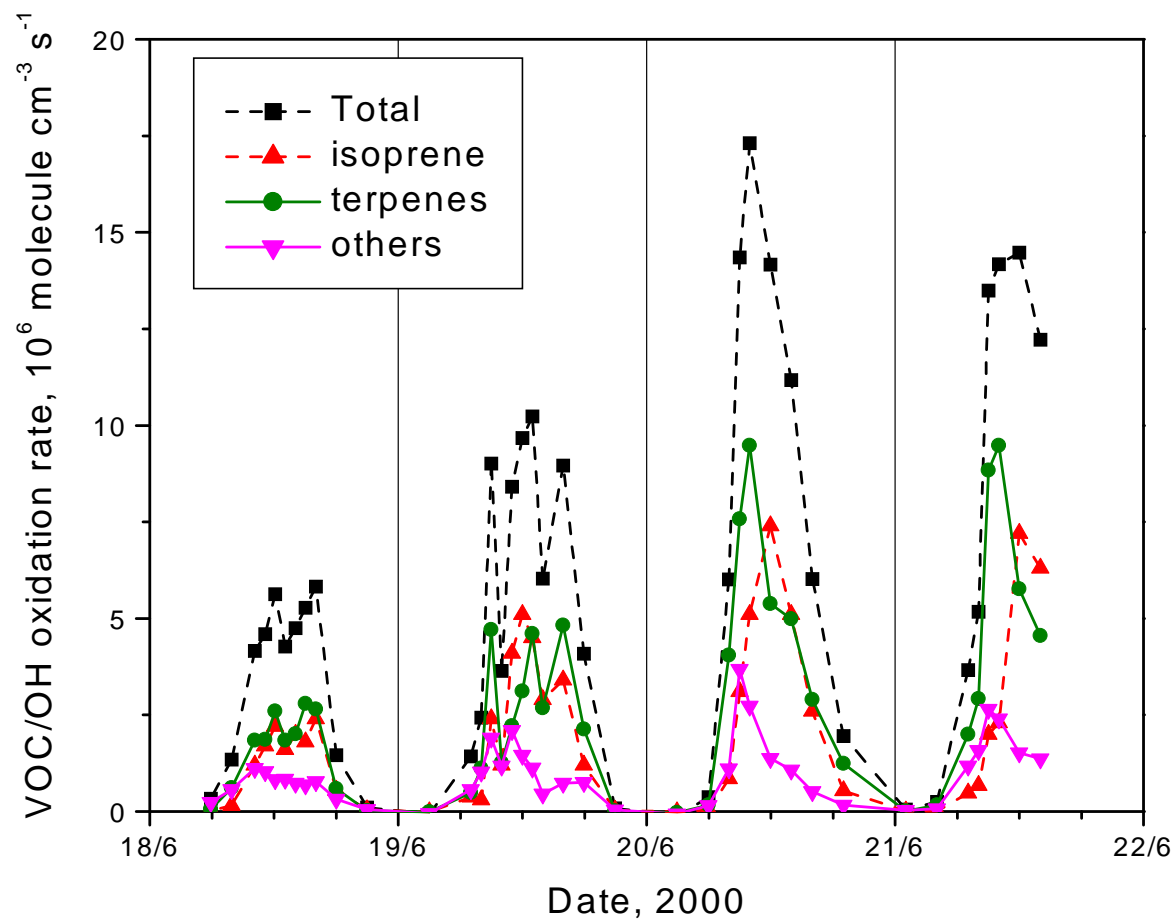

Fig. 5. Plot of the contributions of isoprene, terpenes, and the other NMHCs to the total oxidation rate of NMHC by OH.

at night, particularly of isoprene. Mixing ratios for the sum of all measured anthropogenic alkenes reached nearly $500 \mathrm{pptv}$ during the early morning on 19 and 21 June. This may have allowed significant $\mathrm{RO}_{\mathrm{X}}$ production by night-time oxidation.

The profiles of various groups of NMHCs are shown in Fig. 4. The upper panel shows the total concentrations for three groups of NMHCs which are predominantly anthropogenic in origin: alkenes (not including isoprene or terpenes), aromatic compounds, and a group including alkanes, alkynes and cyclic NMHCs. The profiles of isoprene and various measured terpenes are shown in the lower panel. These exhibit marked diurnal variations consistent with their strong biogenic emission sources. The biogenic emissions of isoprene increase with light intensity and temperature, whereas emissions of monoterpenes are only dependent on temperature (Guenther et al., 1993). This results in a maximum mixing ratio of up to $600 \mathrm{pptv}$ around noon for isoprene, and a broad maximum in the afternoon for the monoterpenes, e.g. of up to $200 \mathrm{pptv}$ for $\alpha$-pinene. The nighttime mixing ratios of terpenes decreased to below 20 pptv because the nighttime biogenic emissions mostly took place within the boundary layer. The breakup of the nocturnal inversion layer in the morning led to a peak in the terpene mixing ratios between 8:00 and 11:00 CET.

$\mathrm{OH}$ oxidation rates (defined by $k_{i} \times\left[\mathrm{NMHC}_{i}\right] \times[\mathrm{OH}]$, where $k_{i}$ is the rate constant, see Table 3) were calculated for individual NMHCs on the basis of the $\mathrm{OH}$ and NMHC measurements. The resulting total NMHC oxidation rate due to $\mathrm{OH}$ is plotted in Fig. 5, along with the individual rates for isoprene and the terpenes. As is to be expected from the $\mathrm{OH}$ profile, the highest oxidation rate occurred during morning and around noon, between approximately 09:00 and 13:00 CET. The highest conversion rate for an individual compound was observed for isoprene, and reached over $7 \times 10^{6}$ molecules $\mathrm{cm}^{-3} \mathrm{~s}^{-1}$ on 20 June. The total oxidation rate of the sum of all monoterpenes was also relatively high, and was equal or greater than the total conversion rate of all other NMHCs taken together.

Although no $\mathrm{NO}_{3}$ measurements were available, it can be assumed that $\mathrm{NO}_{3}$ radical concentrations built up after sunset from the reaction of $\mathrm{NO}_{2}$ with ozone. The NMHC data show evidence for the presence of $\mathrm{NO}_{3}$ radicals, since the rapid decline after 18:00 CET of those biogenic VOC which are less reactive towards ozone, e.g. isoprene, $\beta$-pinene, camphene and 3-carene, cannot be explained by $\mathrm{OH}$ and ozone chemistry alone. Consequently, it is likely that $\mathrm{RO}_{\mathrm{x}}$ production from $\mathrm{NO}_{3}$-alkene reactions contributed to the observed nighttime $\mathrm{RO}_{\mathrm{X}}$ levels. Not all the peroxy radical products of $\mathrm{NO}_{3}$-alkene reactions will be detected by the chemical amplifier, as radical amplification is prevented by the thermal decomposition of the alkoxy radicals of certain $\beta$-nitrooxy peroxy radicals. Model results by Ashbourn et al. (1998) do indicate that $70-80 \%$ of ambient nighttime peroxy radicals would be detected by a chemical amplifier. Thus it is expected that these peroxy radicals will also contribute to the nighttime peroxy radical mixing ratio measured during 


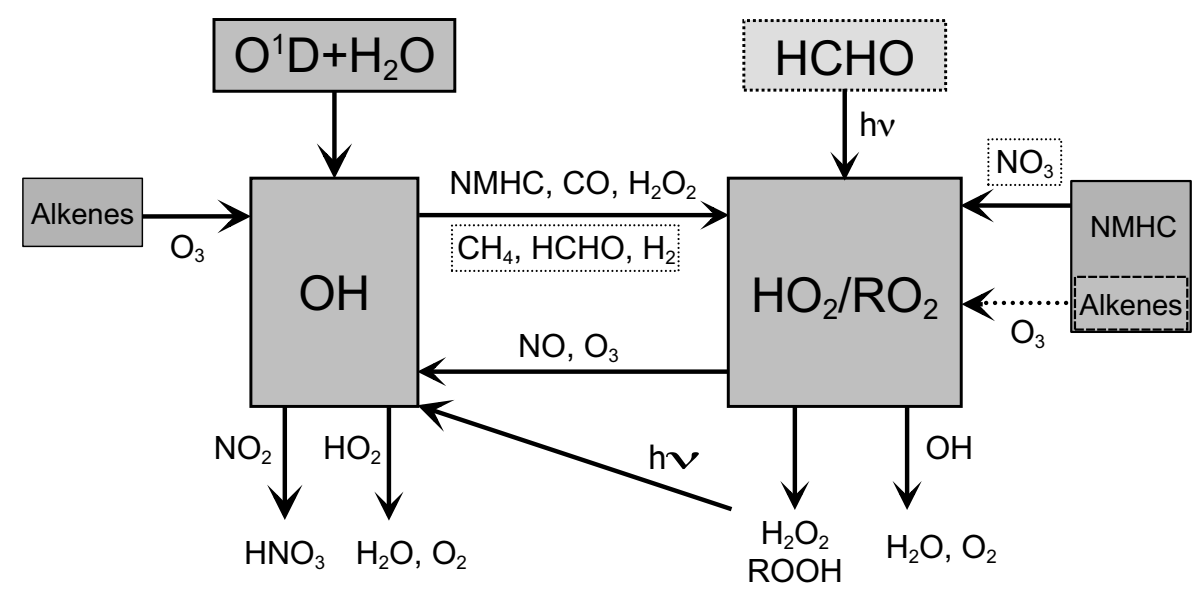

Fig. 6. Block diagram of the chemistry considered in the photostationary state calculations. Components whose concentrations were approximated are indicated by dashed boxes.

HOPE. This will be further discussed in the following section.

The time series for the mixing ratios of $\mathrm{H}_{2} \mathrm{O}_{2}$ and organic hydroperoxides show more or less regular variation, however no such variations were observed during concurrent calibration measurements. Thus, although the reason for these variations is not yet understood, we could find no evidence that the fluctuations were caused by instrumental artifacts. The impact of these compounds on the $\mathrm{OH}$ and $\mathrm{RO}_{\mathrm{X}}$ radicals is nevertheless rather small.

\section{Discussion}

\subsection{Photostationary state radical balance model}

In order to investigate the consistency of the measurements and our current understanding of atmospheric radical chemistry, the concentrations of $\mathrm{OH}$ and total $\mathrm{RO}_{2}^{*}$ were calculated using simple uncoupled balance equations. The intention was not to run a full-scale model, but rather to perform a simple check of the consistency of our measurements and to investigate various features in the daily profiles of both $\mathrm{OH}$ and $\mathrm{RO}_{\mathrm{X}}$. With the limited number of compounds measured in the present study, a full model including biogenic VOC chemistry would require substantial assumptions and simplifications and would result in substantial uncertainties with respect to the calculated concentrations. The measured data from 18-21 June were used as input parameters for solving the balance equations.

Photostationary state conditions were assumed for each of the radical species under consideration, i.e. both $\mathrm{OH}$ and $\mathrm{RO}_{2}^{*}$ were assumed to be sufficiently short-lived that they remain in steady state with the ambient conditions. Under pho- tostationary state conditions, the production and loss rates for each of the radicals are assumed to be equal.

$\frac{d[\mathrm{X}]}{d t} \approx 0=P_{\mathrm{X}}-L_{\mathrm{X}}$

where $P_{\mathrm{X}}$ represents the total production rate for radical $\mathrm{X}$, and $L_{\mathrm{X}}$ is the corresponding loss rate. The balance equation for each radical can then be solved, and the concentration of that species can be calculated when the input parameters are known. The concentrations of all measured trace gases, including radicals other than the specific radical under consideration, were used as input for calculating each of the radicals. Thus, the measured $\mathrm{OH}$ concentration was used to calculate the $\mathrm{RO}_{2}^{*}$ mixing ratio, and the measured $\mathrm{RO}_{\mathrm{X}}$ mixing ratio to calculate the $\mathrm{OH}$ concentration. As discussed above, $\mathrm{RO}_{\mathrm{X}}$ is effectively equal to $\mathrm{RO}_{2}^{*}$ and will be used to refer to both measured $\mathrm{RO}_{\mathrm{X}}$ and calculated $\mathrm{RO}_{2}^{*}$. Figure 6 is a block diagram showing the chemical interactions included in this simple uncoupled balance-model. Heterogeneous loss was not considered in the balance since it was assumed to be negligible. In recent studies, heterogeneous loss was calculated to reduce the $\mathrm{RO}_{\mathrm{X}}$ concentration by up to about $15 \%$ (Carslaw et al., 2002, 2001; Cantrell et al., 1997a).

The corresponding radical concentration was calculated for the times for which measured NMHC data were available. The results of the model calculations are compared with the measurements and discussed in the following section. The reactions and rate coefficients included in the radical balance calculations are listed in Table 2. The rate coefficients for the oxidation of individual hydrocarbon species by $\mathrm{OH}$ are listed in Table 3. The primary production rate of $\mathrm{OH}(\mathrm{de}-$ noted $\mathrm{P}(\mathrm{OH})$, No. 1 in Table 2) was calculated using measured ambient $\mathrm{O}_{3}$ and $\mathrm{H}_{2} \mathrm{O}$ concentrations and the measured photolysis rate of $\mathrm{O}_{3}, \mathrm{j}_{\mathrm{O}^{1} \mathrm{D}}$. The photolysis rates for $\mathrm{H}_{2} \mathrm{O}_{2}$ and $\mathrm{HCHO}$ were calculated using the System for Transfer of Atmospheric Radiation (STAR) transfer model developed by 
Table 2. Reactions and rate coefficients used in the photostationary state calculations of the radical concentrations. The role played by the relevant reaction in the respective radical cycle is denoted by $\mathrm{P}$ for Production and $\mathrm{L}$ for Loss. All rate coefficients have been calculated for a relevant average temperature of $293 \mathrm{~K}$ using the temperature dependent rate equations from Atkinson et al. (2001) (where available; otherwise $k$ (298) was used). Rates for termolecular reactions were calculated for $\mathrm{P}=908 \mathrm{hPa}$

\begin{tabular}{|c|c|c|c|c|c|}
\hline \multirow[t]{2}{*}{ No. } & \multirow[t]{2}{*}{ Reaction } & \multicolumn{3}{|c|}{ Role in cycle for } & \multirow{2}{*}{$\begin{array}{c}k(293 \mathbf{K}) \\
\mathbf{c m}^{3} \text { molecule }^{-1} \mathbf{s}^{-1}\end{array}$} \\
\hline & & $\mathbf{O H}$ & $\mathrm{HO}_{2}$ & $\mathbf{R O}_{2}$ & \\
\hline \multicolumn{6}{|c|}{ PHOTOLYSIS REACTIONS } \\
\hline & $\mathrm{O}_{3}+\mathrm{h} v \stackrel{\mathrm{H}_{2} \mathrm{O}}{\longrightarrow} 2 \mathrm{OH}+\mathrm{O}_{2}$ & $\mathrm{P}$ & & & measured $^{a}$ \\
\hline 2. & $\mathrm{H}_{2} \mathrm{O}_{2}+\mathrm{h} v \longrightarrow 2 \mathrm{OH}$ & $\mathrm{P}$ & & & $\mathrm{j}_{\mathrm{H}_{2} \mathrm{O}_{2}}$, STAR Model \\
\hline & $\mathrm{HCHO}+\mathrm{h} v \stackrel{\mathrm{O}_{2}}{\longrightarrow} 2 \mathrm{HO}_{2}+\mathrm{CO}$ & & $\mathrm{P}$ & & $\mathrm{j}_{\mathrm{HCHO}}$, STAR Model \\
\hline \multicolumn{6}{|c|}{ OH REACTIONS } \\
\hline 4. & $\mathrm{OH}+\mathrm{RH} \longrightarrow \mathrm{R}+\mathrm{H}_{2} \mathrm{O} \stackrel{\mathrm{O}_{2}}{\longrightarrow} \mathrm{RO}_{2}+\mathrm{H}_{2} \mathrm{O}$ & $\mathrm{L}$ & & $\mathrm{P}$ & various $^{b}$ \\
\hline 5. & $\mathrm{OH}+\mathrm{HCHO} \longrightarrow \mathrm{HCO}+\mathrm{H}_{2} \mathrm{O} \stackrel{\mathrm{O}_{2}}{\longrightarrow} \mathrm{HO}_{2}+\mathrm{CO}+\mathrm{H}_{2} \mathrm{O}$ & $\mathrm{L}$ & $P$ & & $9.2 \times 10^{-12}$ \\
\hline 6. & $\mathrm{OH}+\mathrm{CO} \longrightarrow \mathrm{H}+\mathrm{CO}_{2} \stackrel{\mathrm{O}_{2}}{\longrightarrow} \mathrm{HO}_{2}+\mathrm{CO}_{2}$ & $\mathrm{~L}$ & $\mathrm{P}$ & & $2.0 \times 10^{-13 c}$ \\
\hline 7. & $\mathrm{OH}+\mathrm{NO}_{2} \stackrel{\mathrm{M}}{\longrightarrow} \mathrm{HNO}_{3}$ & $\mathrm{~L}$ & & & $1.5 \times 10^{-11}$ \\
\hline 8. & $\mathrm{OH}+\mathrm{H}_{2} \longrightarrow \mathrm{H}+\mathrm{H}_{2} \mathrm{O} \stackrel{\mathrm{O}_{2}}{\longrightarrow} \mathrm{HO}_{2}+\mathrm{H}_{2} \mathrm{O}$ & $\mathrm{L}$ & $\mathrm{P}$ & & $6.7 \times 10^{-15}$ \\
\hline 9. & $\mathrm{OH}+\mathrm{H}_{2} \mathrm{O}_{2} \longrightarrow \mathrm{HO}_{2}+\mathrm{H}_{2} \mathrm{O}$ & $\mathrm{L}$ & $P$ & & $1.7 \times 10^{-12}$ \\
\hline & $\mathrm{OH}+\mathrm{HO}_{2} \longrightarrow \mathrm{H}_{2} \mathrm{O}+\mathrm{O}_{2}$ & $\mathrm{~L}$ & $\mathrm{~L}$ & & $1.1 \times 10^{-10}$ \\
\hline \multicolumn{6}{|c|}{$\mathrm{HO}_{2}$ REACTIONS } \\
\hline 11. & $\mathrm{HO}_{2}+\mathrm{NO} \longrightarrow \mathrm{OH}+\mathrm{NO}_{2}$ & $\mathrm{P}$ & $\mathrm{L}$ & & $8.8 \times 10^{-12}$ \\
\hline 12. & $\mathrm{HO}_{2}+\mathrm{O}_{3} \longrightarrow \mathrm{OH}+2 \mathrm{O}_{2}$ & $\mathrm{P}$ & $\mathrm{L}$ & & $2.0 \times 10^{-15}$ \\
\hline 13. & $\mathrm{HO}_{2}+\mathrm{HO}_{2} \longrightarrow \mathrm{H}_{2} \mathrm{O}_{2}+\mathrm{O}_{2}$ & & $\mathrm{~L}$ & & $5.0 \times 10^{-12}$ \\
\hline 14. & $\mathrm{HO}_{2}+\mathrm{RO}_{2} \longrightarrow \mathrm{ROOH}+\mathrm{O}_{2}$ & & $\mathrm{~L}$ & $\mathrm{~L}$ & $1.6 \times 10^{-11 d}$ \\
\hline $14 \mathrm{a}$. & $\underset{\mathrm{HO}_{2}}{\mathrm{CH}_{3} \mathrm{O}_{2}} \longrightarrow \mathrm{CH}_{3} \mathrm{OOH}+\mathrm{O}_{2}$ & & $\mathrm{~L}$ & $\mathrm{~L}$ & $5.2 \times 10^{-12}$ \\
\hline $15 \mathrm{a}$. & $\begin{array}{l}\text { EACTIONS } \\
\mathrm{RO}_{2}+\mathrm{NO} \longrightarrow \mathrm{RO}+\mathrm{NO}_{2}\end{array}$ & & & $\mathrm{~L}$ & $9.2 \times 10^{-12 e}$ \\
\hline $15 \mathrm{a}^{\prime}$. & $\mathrm{CH}_{3} \mathrm{O}_{2}+\mathrm{NO} \longrightarrow \mathrm{CH}_{3} \mathrm{O}+\mathrm{NO}_{2}$ & & & $\mathrm{~L}$ & $7.5 \times 10^{-12}$ \\
\hline $15 \mathrm{~b}$. & $\mathrm{RO}_{2}+\mathrm{NO} \longrightarrow \mathrm{RONO}_{2}$ & & & $\mathrm{~L}$ & \\
\hline 16. & $\mathrm{RO}_{2}+\mathrm{RO}_{2} \longrightarrow \mathrm{ROOR}$ & & & $\mathrm{L}$ & \\
\hline $16 \mathrm{a}$. & $\mathrm{CH}_{3} \mathrm{O}_{2}+\mathrm{CH}_{3} \mathrm{O}_{2} \longrightarrow \mathrm{CH}_{3} \mathrm{OOCH}_{3}$ & & & $\mathrm{~L}$ & $3.7 \times 10^{-13}$ \\
\hline \multicolumn{6}{|c|}{ ALKENE REACTIONS } \\
\hline 17. & $\mathrm{O}_{3}+$ Alkene $\longrightarrow \mathrm{RO}_{2}+$ products & & & $\mathrm{P}$ & various \\
\hline 18. & $\mathrm{NO}_{3}+$ Alkene $\longrightarrow \mathrm{RO}_{2}+$ products & & & $\mathrm{P}$ & various \\
\hline
\end{tabular}

${ }^{a}$ Primary production of $\mathrm{OH}$ calculated from measured values; denoted $\mathrm{P}(\mathrm{OH})$

$b$ see Table 3

$c$ for $\mathrm{P}=908 \mathrm{hPa}$

${ }^{d}$ for $\mathrm{R} \geq \mathrm{C}_{2}$; recommended value for $\mathrm{R} \geq \mathrm{C}_{3}$ from Atkinson (1997) was used in Scenario IV; the $\mathrm{C}_{2}$ reaction rate was not considered.

${ }^{e}$ for $\mathrm{R} \geq \mathrm{C}_{2}$; recommended value from Atkinson (1997) was used in Scenario IV.

Ruggaber et al. (1994) and further modified by Schwander et al. (2001). OH production due to the reaction of alkenes with ozone was calculated using the corresponding radical yields compiled by Atkinson (1997).

To solve the equations exactly, the identity and concentration of each of the various organic peroxy radicals present in the air sample would have to be known. Since such detailed measurements are not possible with currently available techniques, a set of assumptions about the chemical behaviour and composition of the peroxy radicals were made and a basic scenario for the calculations was established. The effects of these assumptions on the model results will be discussed in Sect. 4.4.

In the base case scenario, the model was simplified by assuming that $\mathrm{HO}_{2}$ and $\mathrm{CH}_{3} \mathrm{O}_{2}$ were the only peroxy radicals present, and that they were present in equal concentrations.

$$
\begin{aligned}
& {\left[\mathrm{HO}_{2}\right]_{\text {model }}=\left[\mathrm{RO}_{2}\right]_{\text {model }}=0.5\left[\mathrm{RO}_{\mathrm{x}}\right]_{\text {measured }} \text { for } \mathrm{OH}} \\
& {\left[\mathrm{HO}_{2}\right]_{\text {model }}=\left[\mathrm{RO}_{2}\right]_{\text {model }}=0.5\left[\mathrm{RO}_{2}^{*}\right]_{\text {model }} \text { for } \mathrm{RO}_{2}}
\end{aligned}
$$

Measurements by Mihelcic et al. (1993) and Mihelcic et al. (2001) have shown that for daytime conditions, $\mathrm{HO}_{2}$ and 
Table 3. Daytime average hydrocarbon mixing ratios, measurement accuracies, and $\mathrm{OH}$ reaction rate constants used in the steady state model calculations

\begin{tabular}{|c|c|c|c|c|}
\hline Substance Name & $\begin{array}{c}\text { Average Mixing Ratio } \\
\text { 07:00-17:00 CET } \\
\text { pptv }\end{array}$ & $\begin{array}{c}\text { Accuracy } \\
\text { pptv }\end{array}$ & $\begin{array}{c}k_{\mathrm{OH}}\left(293 \mathrm{~K}^{a}, 908 \mathrm{hPa}\right) \\
\mathrm{cm}^{3} \text { molecule }^{-1} \mathrm{~s}^{-1}\end{array}$ & Ref. \\
\hline methane & $1.842 \mathrm{ppmv}^{b}$ & & $6.4 \times 10^{-15}$ & Atkinson et al. (1999) \\
\hline ethyne & 202.1 & 31.5 & $7.8 \times 10^{-13}$ & Atkinson (1994) \\
\hline ethene & 162.0 & 11.3 & $8.99 \times 10^{-12}$ & Atkinson et al. (1999) \\
\hline ethane & 931.1 & 52.7 & $2.36 \times 10^{-13}$ & Atkinson et al. (1999) \\
\hline propyne & 5.0 & 2.5 & $5.9 \times 10^{-12 *}$ & Atkinson (1994) \\
\hline propene & 58.9 & 7.1 & $3.0 \times 10^{-11}$ & Atkinson et al. (1999) \\
\hline propane & 193.0 & 11.2 & $1.07 \times 10^{-12}$ & Atkinson et al. (1999) \\
\hline 1,3-butadiene & 24.6 & 3.2 & $6.83 \times 10^{-11}$ & Atkinson (1997) \\
\hline trans-2-butene & 8.3 & 7.5 & $6.60 \times 10^{-11}$ & Atkinson (1997) \\
\hline 1-butene & 2.8 & 4.2 & $3.22 \times 10^{-11}$ & Atkinson (1997) \\
\hline 2-methylpropene & 23.3 & 22.0 & $5.28 \times 10^{-11}$ & Atkinson (1997) \\
\hline cis-2-butene & 5.2 & 5.0 & $5.79 \times 10^{-11}$ & Atkinson (1997) \\
\hline 2-methylpropane & 50.3 & 3.2 & $2.15 \times 10^{-12}$ & Atkinson (1997) \\
\hline isoprene & 308.8 & 67.2 & $1.03 \times 10^{-10}$ & Atkinson (1997) \\
\hline n-butane & 86.0 & 5.0 & $2.34 \times 10^{-12}$ & Atkinson et al. (1999) \\
\hline cyclopentane & 3.9 & 0.8 & $4.92 \times 10^{-12}$ & Atkinson (1997) \\
\hline trans-2-pentene & 0.8 & 1.6 & $6.7 \times 10^{-11 *}$ & Atkinson (1997) \\
\hline 1-pentene & 6.2 & 3.0 & $3.14 \times 10^{-11 *}$ & Atkinson (1997) \\
\hline cis-2-pentene & 0.7 & 1.7 & $6.50 \times 10^{-11 *}$ & Atkinson (1997) \\
\hline 2-methylbutane & 188.9 & 12.0 & $3.7 \times 10^{-12 *}$ & Atkinson (1997) \\
\hline n-pentane & 67.5 & 5.1 & $3.91 \times 10^{-12}$ & Atkinson (1997) \\
\hline benzene & 69.0 & 6.0 & $1.17 \times 10^{-12}$ & Semadeni et al. (1995) \\
\hline methylcyclopentane & 11.8 & 2.4 & $6.8 \times 10^{-12 *}$ & Kwok and Atkinson (1995) \\
\hline cyclohexane & 13.3 & 2.1 & $7.10 \times 10^{-12}$ & Atkinson (1997) \\
\hline 1-hexene & 3.4 & 1.2 & $3.70 \times 10^{-11 *}$ & Atkinson (1997) \\
\hline n-hexane & 15.3 & 1.4 & $5.40 \times 10^{-12}$ & Atkinson (1997) \\
\hline 2-methylpentane & 37.3 & 2.8 & $5.30 \times 10^{-12 *}$ & Atkinson (1997) \\
\hline 3-methylpentane & 23.5 & 1.9 & $5.40 \times 10^{-12 *}$ & Atkinson (1997) \\
\hline 2,3-dimethylbutane & 4.8 & 1.7 & $5.75 \times 10^{-12}$ & Atkinson (1997) \\
\hline toluene & 106.6 & 7.1 & $6.4 \times 10^{-12}$ & Semadeni et al. (1995) \\
\hline methylcyclohexane & 4.1 & 0.8 & $1.00 \times 10^{-11 *}$ & Atkinson (1997) \\
\hline 2-methylhexane & 9.3 & 1.4 & $5.10 \times 10^{-12 *}$ & Kwok and Atkinson (1995) \\
\hline 2,3-dimethylpentane & 4.2 & 1.6 & $6.10 \times 10^{-12 *}$ & Kwok and Atkinson (1995) \\
\hline n-heptane & 15.7 & 1.4 & $6.98 \times 10^{-12}$ & Atkinson (1997) \\
\hline ethylbenzene & 30.4 & 1.8 & $7.10 \times 10^{-12 *}$ & Atkinson (1994) \\
\hline m,p-xylene & 68.8 & 8.0 & $1.90 \times 10^{-11 *}$ & Atkinson (1994) \\
\hline o-xylene & 29.9 & 2.1 & $1.37 \times 10^{-11 *}$ & Atkinson (1994) \\
\hline n-octane & 5.0 & 0.9 & $8.60 \times 10^{-12}$ & Atkinson (1997) \\
\hline 3-methylheptane & 3.9 & 0.7 & $8.56 \times 10^{-12 *}$ & Kwok and Atkinson (1995) \\
\hline 4-methylheptane & 5.5 & 1.0 & $8.56 \times 10^{-12 *}$ & Kwok and Atkinson (1995) \\
\hline
\end{tabular}

a A star denotes a rate coefficient for $298 \mathrm{~K}$

${ }^{b}$ Average value for June 2002 measured at Schauinsland, see text 
Table 3. continued

\begin{tabular}{|c|c|c|c|c|}
\hline Substance Name & $\begin{array}{c}\text { Average Mixing Ratio } \\
\text { 07:00-17:00 CET } \\
\text { pptv }\end{array}$ & pptv & $\begin{array}{c}k_{\mathrm{OH}}\left(293 \mathrm{~K}^{a}, 908 \mathrm{hPa}\right) \\
\mathbf{c m}^{3} \text { molecule }^{-1} \mathrm{~s}^{-1}\end{array}$ & Ref. \\
\hline n-propylbenzene & 2.6 & 1.0 & $5.70 \times 10^{-12 *}$ & Atkinson (1994) \\
\hline 1,3,5-trimethylbenzene & 2.1 & 0.4 & $5.75 \times 10^{-11 *}$ & Atkinson (1994) \\
\hline 1,2,4-trimethylbenzene & 10.4 & 1.9 & $3.75 \times 10^{-11 *}$ & Atkinson (1994) \\
\hline m-ethyltoluene & 6.9 & 2.1 & $1.71 \times 10^{-11 *}$ & Atkinson (1994) \\
\hline p-ethyltoluene & 3.3 & 1.0 & $1.14 \times 10^{-11} *$ & Atkinson (1994) \\
\hline n-nonane & 9.6 & 2.9 & $9.91 \times 10^{-12}$ & Atkinson (1997) \\
\hline i-butylbenzene & 0.6 & 0.6 & $8.17 \times 10^{-12 *}$ & Kwok and Atkinson (1995) \\
\hline sec-butylbenzene & 2.7 & 1.1 & $8.17 \times 10^{-12} *$ & Kwok and Atkinson (1995) \\
\hline p-cymene & 11.5 & 3.5 & $1.51 \times 10^{-11}$ & Corchnoy and Atkinson (1990) \\
\hline 1-methyl-3-propylbenzene & 1.4 & 0.4 & $1.47 \times 10^{-11 *}$ & Kwok and Atkinson (1995) \\
\hline$\alpha$-pinene & 131.3 & 39.5 & $5.51 \times 10^{-11}$ & Atkinson (1997) \\
\hline$\beta$-pinene & 62.0 & 19.2 & $8.05 \times 10^{-11}$ & Atkinson (1997) \\
\hline camphene & 22.7 & 7.4 & $5.3 \times 10^{-11}$ & Atkinson (1997) \\
\hline sabinene & 59.2 & 35.0 & $1.17 \times 10^{-10}$ & Atkinson (1997) \\
\hline myrcene & 15.9 & 5.7 & $2.15 \times 10^{-10}$ & Atkinson (1997) \\
\hline 3-carene & 38.3 & 14.0 & $8.8 \times 10^{-11}$ & Atkinson (1997) \\
\hline$\alpha$-terpinene ${ }^{c}$ & 2.7 & 2.7 & $3.63 \times 10^{-10}$ & Atkinson (1997) \\
\hline terpinolene & 2.9 & 1.7 & $2.25 \times 10^{-10}$ & Atkinson (1997) \\
\hline$\gamma$-terpinene & 5.4 & 2.7 & $1.77 \times 10^{-10}$ & Atkinson (1997) \\
\hline limonene & 23.9 & 7.5 & $1.71 \times 10^{-10}$ & Atkinson (1997) \\
\hline tricyclene & 10.0 & 3.4 & $2.86 \times 10^{-12} *$ & Atkinson and Aschmann (1992) \\
\hline 1,8-cineol & 29.2 & 14.5 & $1.11 \times 10^{-11 *}$ & Corchnoy and Atkinson (1990) \\
\hline n-undecane & 6.1 & 2.4 & $1.29 \times 10^{-11 *}$ & Atkinson (1997) \\
\hline n-dodecane & 2.3 & 0.7 & $1.39 \times 10^{-11 *}$ & Atkinson (1997) \\
\hline n-tridecane & 1.3 & 0.6 & $1.60 \times 10^{-11 *}$ & Atkinson (1997) \\
\hline
\end{tabular}

${ }^{a}$ A star denotes a rate coefficient for $298 \mathrm{~K}$

${ }^{c}$ Due to its high inaccuracy, $\alpha$-terpinene was excluded from the data set for the model calculations, see description of the NMHC system for discussion.

$\mathrm{RO}_{2}$ are often present in nearly equal amounts in the continental atmosphere. As the concentration of $\mathrm{OH}$ is typically two orders of magnitude less than that of $\mathrm{HO}_{2}$, the contribution of $\mathrm{OH}$ to the measured $\mathrm{RO}_{\mathrm{x}}$ concentration is negligible. It is to be expected that $\mathrm{CH}_{3} \mathrm{O}_{2}$ constitutes a significant fraction of the organic radicals, as it is a product of the oxidation chains for most hydrocarbon species. Consequently, the reaction rates for the methyl peroxy radical, $\mathrm{CH}_{3} \mathrm{O}_{2}\left(k_{14 a}\right.$, $k_{16 \mathrm{a}}$ ) were used for reactions involving $\mathrm{RO}_{2}$.

The production of $\mathrm{RO}_{\mathrm{X}}$ radicals via the oxidation of $\mathrm{NMHCs}$ by $\mathrm{O}_{3}$ was not included in the base run. Ozonolysis of biogenic alkenes may lead to $\mathrm{RO}_{\mathrm{x}}$ production (Atkinson, 1997), particularly at the high concentrations of both ozone and biogenic alkenes present during the day (see Figs. 2 and 4). However, the available kinetic data on NMHC ozonolysis does not readily allow the yields of $\mathrm{HO}_{2}$ or $\mathrm{RO}_{2}$ to be calculated. Using the Master Chemical Mechanism (MCM), Carslaw et al. (2002) found that this source of $\mathrm{RO}_{\mathrm{X}}$ made only a minor contribution to the total $\mathrm{RO}_{\mathrm{X}}$ production (see also Sect. 4.4).
Measured concentrations were used for all trace gases in the model except for $\mathrm{HCHO}, \mathrm{CH}_{4}$ and $\mathrm{H}_{2}$, which were not measured. The concentration of $\mathrm{CH}_{4}$ was approximated using the average value of 1.842 ppmv for June 2002 measured at the UBA station at Schauinsland in Southern Germany (Umweltbundesamt, 2001). An $\mathrm{H}_{2}$ concentration of $500 \mathrm{ppbv}$, which is typical for the Northern Hemisphere (Novelli et al., 1999), was used to approximate the $\mathrm{H}_{2}$ concentration. A constant mixing ratio of $3 \mathrm{ppbv}$ was assumed for formaldehyde, $\mathrm{HCHO}$, as a proxy for the oxygenated NMHCs. This assumption seems to be reasonable based on the concentrations of formaldehyde, acetaldehyde, acetone, methylvinylketone, and methacrolein typically measured in rural environments under summertime conditions (e.g. Lamanna and Goldstein, 1999; Benning and Wahner, 1998; Goldan et al., 1997; Solberg et al., 1996; Montzka et al., 1995).

The uncertainties of radical concentrations calculated from numeric solutions of coupled balance equations have been estimated in previous studies using a Monte Carlo 


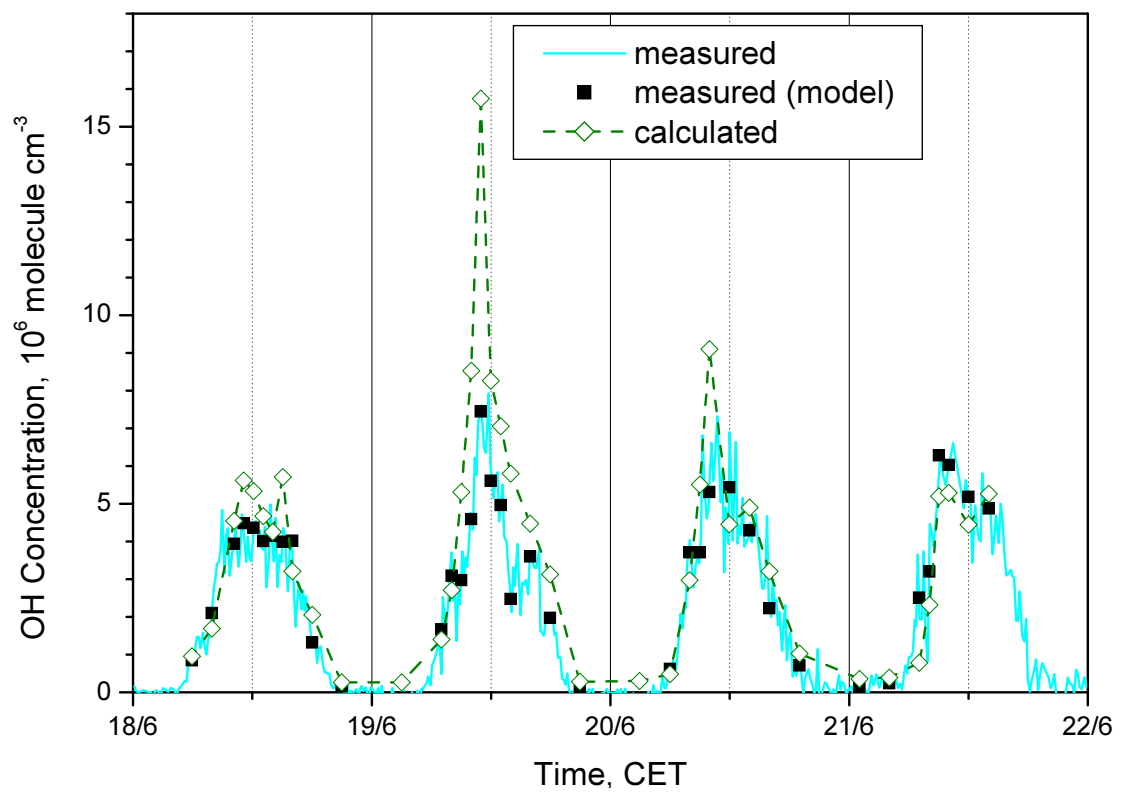

Fig. 7. Plot of the observed $\mathrm{OH}$ concentration and the concentration derived from photostationary state radical balance calculations for the period 18-21 June, 2000. The measured $\mathrm{OH}$ concentration is represented by the solid line. The $\mathrm{OH}$ concentration at the same time as the NMHC measurements are shown as solid squares.

approach (e.g. Thompson and Stewart, 1991). A simpler approach is used in the present study since the radical concentrations are calculated using uncoupled balance equations. This allows error propagation assuming independent error contributions to be applied. This includes the uncertainties of the trace gases measurements and the corresponding reaction rate constants, as well as errors due to the inherent model assumptions. During HOPE 2000, emissions from biogenic NMHC sources strongly influenced the local photochemistry. For this reason, substantial uncertainties in the calculations could have been produced due to (a) important NMHC compounds which were not included in the measurement programme, especially oxidation products of biogenic VOCs, and/or (b) the unknown speciation and chemistry of the peroxy radicals originating from the oxidation of biogenic VOCs. However, assessing the impact of these basically unknown parameters is highly uncertain and will be discussed in Sect. 4.4. As a first estimate, the uncertainty of the calculated radical concentrations are estimated here by assuming that the base case scenario is valid.

Major error contributions were due to (1) the uncertainty in the measured radical concentration used to constrain the balance equation, (2) the uncertainty in the turn-over-rate of the NMHC $\left(\sum k_{i} \times\left[\mathrm{NMHC}_{i}\right]\right)(\sim 23 \%)$, and (3) the assumed HCHO concentration $(\sim 50 \%)$. The estimated nighttime concentration of NO (see Sect. 2) is uncertain by a factor of 2 . The total uncertainties in the calculated concentrations of $\mathrm{OH}$ and $\mathrm{RO}_{\mathrm{X}}$ are approximately $42 \%$ and $45 \%(2 \sigma)$, respectively, calculated using the technique of error propagation. For nighttime conditions, the error in the calculated $\mathrm{RO}_{\mathrm{X}}$ is approximately $6 \mathrm{pptv}$. This is mainly due to the effect of $\mathrm{OH}$ concentrations below the detection limit.

The atmospheric lifetimes of $\mathrm{OH}$ and $\mathrm{RO}_{2}$ were calculated on the basis of the respective modelled radical fluxes. The calculated lifetime of $\mathrm{OH}$ was $\leq 0.5$ seconds throughout the four days considered using the model. The $\mathrm{RO}_{\mathrm{X}}$ lifetime was much longer due to the lower reactivity of peroxy radicals. For daytime conditions, it was estimated to be less than $3 \mathrm{~min}$, and for nighttime conditions (approximately 19:00 to 07:00 CET) the lifetime was less than $8 \mathrm{~min}$ for the base case. The $\mathrm{RO}_{2}$ lifetime is expected to be even longer than this under real nighttime conditions, as $\mathrm{HO}_{2}$ is removed more quickly than $\mathrm{RO}_{2} . \mathrm{HO}_{2}$ is the main nighttime sink of $\mathrm{RO}_{2}$, so that following the drop in $\mathrm{HO}_{2}$ mixing ratios $\mathrm{RO}_{2}$ levels will drop much more slowly.

Modelling of the nighttime chemistry is complicated by the unknown production rate of $\mathrm{RO}_{\mathrm{X}}$ via the oxidation of NMHCs by the nitrate radical (Reaction 18 in Table 2), and the production of $\mathrm{OH}$ from alkene-ozone reactions (Reaction 17 in Table 2). The nitrate radical was not measured during HOPE 2000. However, the production rate of $\mathrm{NO}_{3}$ radicals can be calculated from the $\mathrm{O}_{3}$ and $\mathrm{NO}_{2}$ concentrations. During HOPE 2000, the lifetime of $\mathrm{NO}_{3}$ radicals with respect to the reaction with NMHC was estimated to range from $25 \mathrm{~s}$ to $130 \mathrm{~s}$ at night, which is comparable or slightly longer than the lifetime of $20 \mathrm{~s}$ to $50 \mathrm{~s}$ estimated for the reaction of $\mathrm{NO}_{3}$ with $\mathrm{NO}_{2}$. The reaction of $\mathrm{NO}_{3}$ with $\mathrm{NO}$ is of minor importance, since at 6 pptv NO the lifetime of $\mathrm{NO}_{3}$ with regard to this reaction is more than $300 \mathrm{~s}$. Since the nighttime temperature was about $20^{\circ} \mathrm{C}, \mathrm{N}_{2} \mathrm{O}_{5}$ could not build up significantly 
due to thermal decomposition. Consequently, heterogenous loss of $\mathrm{N}_{2} \mathrm{O}_{5}$ to aerosol particles was assumed to be a minor loss process for $\mathrm{NO}_{3}$ compared to the reaction of $\mathrm{NO}_{3}$ with NMHCs.

On the basis of these assumptions, the nighttime $\mathrm{NO}_{3}$ mixing ratio is estimated to be in the range of $1-14 \mathrm{pptv}$ with an average of $6 \mathrm{pptv}$. The upper limit for the $\mathrm{RO}_{2}$ production rate due to reactions between $\mathrm{NO}_{3}$ and $\mathrm{NMHC}$ was assumed to be equal to the $\mathrm{NO}_{3}$ production rate. Nighttime $\mathrm{RO}_{2}$ production rates were calculated to be on the order of $10^{6}$ molecule $\mathrm{cm}^{-3} \mathrm{~s}^{-1}$. During the early evening, the ratio between the amount of $\mathrm{NO}_{3}$ lost due to the reaction with $\mathrm{NO}_{2}$ and the amount lost due to the reaction with $\mathrm{NMHC}$ is highest, suggesting that $\mathrm{RO}_{\mathrm{X}}$ production is most likely to be overestimated by the model at this time of the evening. This is also evident in Fig. 9. The $\mathrm{NO}_{3}$ radical is quickly photolysed during daytime, so that the effect of $\mathrm{RO}_{\mathrm{X}}$ production via $\mathrm{NO}_{3}$ oxidation of NMHCs was only considered in the model for nighttime conditions.

\section{2 $\mathrm{OH}$ balance}

The measured $\mathrm{OH}$ concentrations are compared with the results of the photostationary state calculation for $\mathrm{OH}$ in Fig. 7. Considering the 2- $\sigma$ accuracy of $39 \%$ in the $\mathrm{OH}$ measurements and the uncertainties in the model, the results agree well with measurements. While the agreement is good for 18,20 and 21 June, the concentration of $\mathrm{OH}$ was overestimated on 19 June. During the late morning on the 19th, the difference between measured and modelled concentrations was relatively high: At 11:00 CET the measured $\mathrm{OH}$ concentration was $7.4 \times 10^{6}$ molecule $\mathrm{cm}^{-3}$, and was overestimated by about $100 \%$ by the calculated concentration of $15.7 \times 10^{6}$ molecule $\mathrm{cm}^{-3}$. The meteorological parameters, especially wind direction, and the measured chemical parameters do not suggest that there was any significant difference between the conditions on this specific day in comparison with the other three days. The $\mathrm{OH}$ balance as used here is most sensitive to the concentrations of $\mathrm{NO}$ and $\mathrm{RO}_{\mathrm{X}}$ (see Fig. 8). Although the cause of the discrepancy on 19 June remains unclear, it is possible that an additional sink for $\mathrm{OH}$ was present during the late morning advection episode that is not accounted for in the model. On the other hand, the presence of a large unknown $\mathrm{OH}$ sink which was also a $\mathrm{RO}_{\mathrm{X}}$ source could lead to an overestimate of the $\mathrm{RO}_{\mathrm{X}}$ concentration.

The general shape of the $\mathrm{OH}$ diurnal profile, with a maximum in the late morning and lower concentrations in the afternoon, is well reproduced by the photostationary state calculations on all days. Both the calculated and the measured nighttime $\mathrm{OH}$ concentrations were always below the detection limit of $4 \times 10^{5}$ molecules $\mathrm{cm}^{-3}$. This is most likely due to the combined effect of a deviation of the $\mathrm{HO}_{2} / \mathrm{RO}_{2}$ partitioning ratio from 1:1 (as will be discussed in Sect. 4.4),
Table 4. Average contributions of individual source and sink reactions to the $\mathrm{OH}$ balance for the period 18-21 June 2000

\begin{tabular}{|c|c|c|}
\hline & $\begin{array}{c}\text { Daytime Average } \\
\text { 7:00-17:00 CET } \\
10^{6} \text { molec. } \text { cm }^{-3} \mathrm{~s}^{-1}\end{array}$ & $\begin{array}{c}\text { Midday Average } \\
\text { 12:00 CET } \\
10^{6} \text { molec. } \mathrm{cm}^{-3} \mathrm{~s}^{-1}\end{array}$ \\
\hline \multicolumn{3}{|l|}{ SOURCES } \\
\hline $\mathrm{HO}_{2}+\mathrm{NO}$ & 13.2 & 10.6 \\
\hline $\mathrm{P}(\mathrm{OH})$ & 4.6 & 7.8 \\
\hline $\mathrm{HO}_{2}+\mathrm{O}_{3}$ & 0.95 & 1.3 \\
\hline $\mathrm{P}\left(\mathrm{H}_{2} \mathrm{O}_{2}\right)$ & 0.5 & 0.7 \\
\hline $\mathrm{O}_{3}+$ Alkenes & 1.1 & 1.1 \\
\hline Total Sources & 20.2 & 21.4 \\
\hline \multicolumn{3}{|l|}{ SINKS } \\
\hline NMHC & -7.4 & -10.5 \\
\hline $\mathrm{CO}$ & -2.4 & -2.9 \\
\hline $\mathrm{CH}_{4}(1.842 \mathrm{ppmv})$ & -1.0 & -1.2 \\
\hline HCHO (3 ppbv) & -2.6 & -3.2 \\
\hline $\mathrm{H}_{2}+\mathrm{H}_{2} \mathrm{O}_{2}+\mathrm{HO}_{2}$ & -0.8 & -1.1 \\
\hline $\mathrm{NO}_{2}$ & -2.1 & -1.2 \\
\hline Total Sinks & -16.2 & -20.1 \\
\hline
\end{tabular}

and of NO mixing ratios assumed to be at the detection limit of 6 pptv, which is probably too high.

In order to better understand the relative contributions of the individual sources and sinks to the diurnal profile of the $\mathrm{OH}$ concentration, their contributions were calculated using the measured trace gas concentrations (including $\mathrm{RO}_{\mathrm{X}}$ ) and are plotted in Fig. 8. The upper panel shows the contributions of the individual source terms to the total production rate; the lower panel shows the contributions of the sink terms. Table 4 gives the average daytime contribution of the source and sink reactions considered in the model, as well as the contribution at 12:00 CET averaged over the four days considered here.

The dominant source of $\mathrm{OH}$ radicals turned out to be the recycling of $\mathrm{OH}$ via the reaction of $\mathrm{HO}_{2}$ radicals with $\mathrm{NO}$. This was most pronounced during the late morning episodes of elevated $\mathrm{NO}_{\mathrm{X}}$ mixing ratios, when over $50 \%$ of the $\mathrm{OH}$ radicals were produced by this pathway on average. During periods with relatively low NO mixing ratios below about 100 pptv (e.g., on 18 June and on the afternoons of 20 and 21 June) the primary production of $\mathrm{OH}$ via the photolysis of $\mathrm{O}_{3}$ was comparable to the amount of $\mathrm{OH}$ recycled from $\mathrm{HO}_{2}$. Overall, other relevant reactions, e.g. the reaction between $\mathrm{HO}_{2}$ and $\mathrm{O}_{3}$, alkenes and $\mathrm{O}_{3}$, and the photolysis of $\mathrm{H}_{2} \mathrm{O}_{2}$, made only minor contributions to the $\mathrm{OH}$ concentration.

The main sink for $\mathrm{OH}$ was its reaction with NMHCs. This reaction accounted for an average of $46 \%$ of $\mathrm{OH}$ loss between 7:00 and 17:00 CET and for 53\% loss at 12:00 CET. The loss of $\mathrm{OH}$ due to the oxidation of $\mathrm{CO}$ was nearly equal to the loss to be expected for an assumed 3 ppbv HCHO. The 

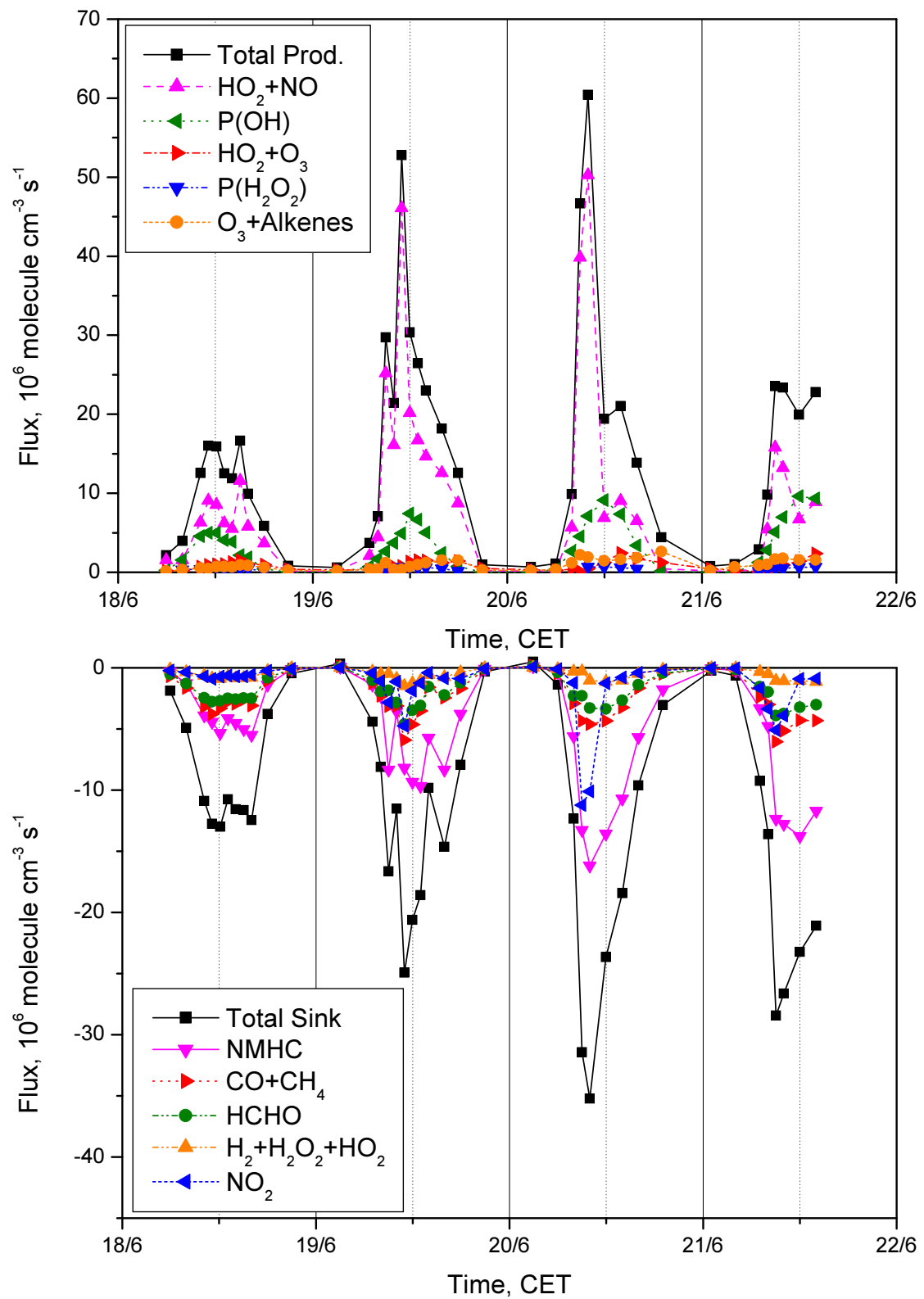

Fig. 8. Plot of the calculated contributions of various sources and sinks of OH for the period 18-21 June, 2000. The scales are different for the two panels.

loss of $\mathrm{OH}$ due to the oxidation of $\mathrm{CH}_{4}$ was even less significant, as was the loss due to reactions with $\mathrm{H}_{2}, \mathrm{H}_{2} \mathrm{O}_{2}$ and $\mathrm{HO}_{2}$. The reaction of $\mathrm{OH}$ with $\mathrm{NO}_{2}$ was generally only a minor sink, but during the mid-morning advection of polluted air to the measurement site it accounted for up to $25 \%$ of the $\mathrm{OH}$ loss.

The $\mathrm{OH}$ sources and sinks derived from measured concentrations shown in Fig. 8 were often not in balance. This imbalance is the origin of the deviations observed in Fig. 7 between the calculated and the measured $\mathrm{OH}$ concentrations. $\mathrm{OH}$ concentrations showed a net maximum in the late morn- ing due to the presence of strongly enhanced levels of NO. This tends to shift radicals from $\mathrm{RO}_{\mathrm{X}}$ to $\mathrm{OH}$ via reactions 11 and 15 in Table 2. In the afternoon hours, however, NO mixing ratios were much lower and the mixing ratios of biogenic hydrocarbons showed a broad maximum. Taken together, these factors caused an increasing shift from $\mathrm{OH}$ towards $\mathrm{RO}_{\mathrm{X}}$ (see following section). 


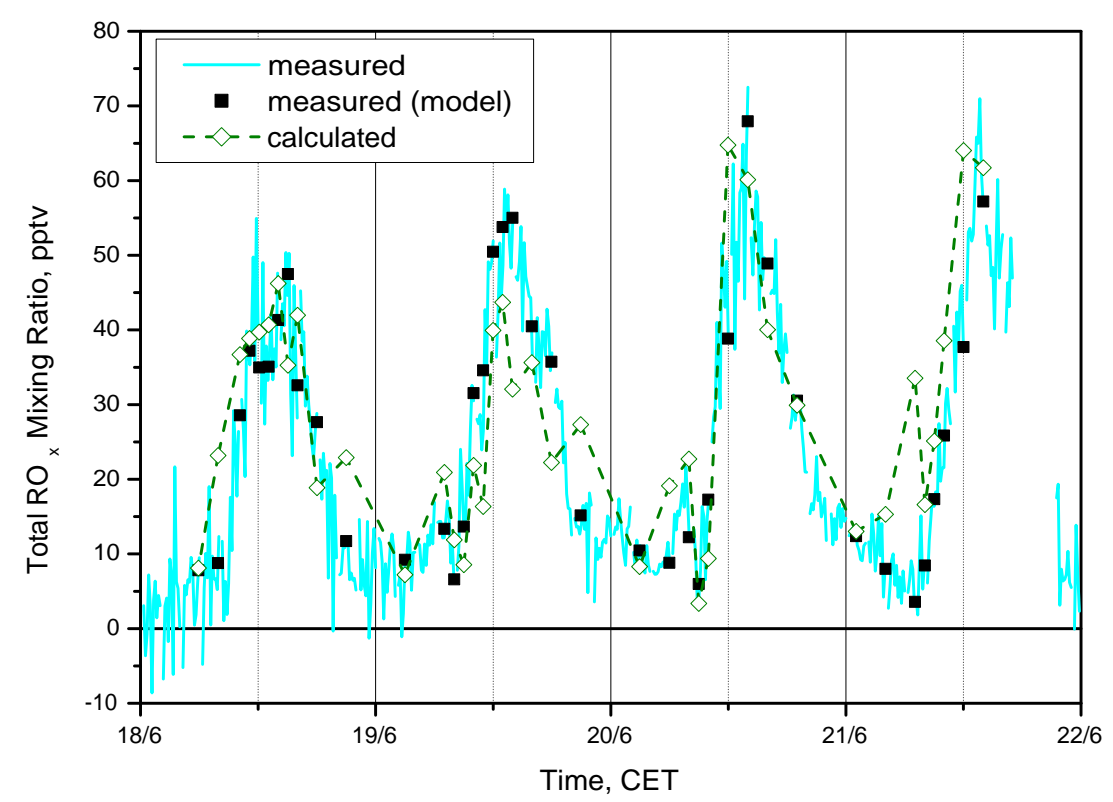

Fig. 9. Plot of the observed $\mathrm{RO}_{\mathrm{X}}$ mixing ratio and the results of the photostationary state radical balance calculations for the period $18-22$ June, 2000. Observations made at the time of the NMHC measurements are shown as solid squares.

\section{$4.3 \mathrm{RO}_{\mathrm{X}}$ balance}

The results for the photostationary state model calculations of $\mathrm{RO}_{\mathrm{X}}$ are compared with the measured $\mathrm{RO}_{\mathrm{X}}$ mixing ratios in Fig. 9. The agreement between the measured and modelled $\mathrm{RO}_{\mathrm{X}}$ mixing ratios was very good for all days except 19 June, considering the uncertainties in both the present simple model approach and the $\mathrm{RO}_{\mathrm{X}}$ measurements. Most of the details in the measured $\mathrm{RO}_{\mathrm{X}}$ profiles are well reproduced by the model. The dip in the mixing ratio for $\mathrm{RO}_{\mathrm{X}}$ at about 8:00 CET is reproduced well on both 19 and 20 June. This dip in the $\mathrm{RO}_{\mathrm{X}}$ mixing ratio coincided with a rapid increase in the $\mathrm{OH}$ concentration in conjunction with the advection of $\mathrm{NO}_{\mathrm{X}}$ enriched boundary layer air from the valley to the measurement site.

The agreement between calculations and measurements for both $\mathrm{OH}$ and $\mathrm{RO}_{\mathrm{X}}$ was not as good on 19 June as on the other days, with deviations for $\mathrm{RO}_{\mathrm{X}}$ of up to $23 \mathrm{pptv}$. This discrepancy was not only observed during the late morning as on other days, but continued into the afternoon hours (Fig. 9). Changes in the composition of the air masses which were not accounted for by the model are probably responsible for this discrepancy.

In analogy to Fig. 8, individual source and sink strengths for $\mathrm{RO}_{\mathrm{X}}$ are shown in Fig. 10. During daytime, $\mathrm{RO}_{\mathrm{X}}$ results from the reactions of $\mathrm{OH}$ with NMHCs, $\mathrm{CO}, \mathrm{H}_{2}$, and $\mathrm{H}_{2} \mathrm{O}_{2}$. $\mathrm{RO}_{\mathrm{X}}$ is also produced as a result of the photolysis of HCHO (Reaction 7; Reaction 3 in Table 2). The combined contribution of the oxidation and photolysis of carbonyl compounds turns out to be the second most important source of $\mathrm{RO}_{\mathrm{X}}$, and is equivalent to slightly more than half of the contribution from the oxidation of $\mathrm{NMHCs}$ by $\mathrm{OH}$. The relative
Table 5. The average contribution of each individual source and sink to the $\mathrm{RO}_{\mathrm{X}}$ balance for the period 18-21 June 2000

\begin{tabular}{|c|c|c|}
\hline & $\begin{array}{c}\text { Daytime Average } \\
\text { 7:00-17:00 } \\
10^{6} \text { molec. } \text { cm }^{-3} \mathrm{~s}^{-1}\end{array}$ & $\begin{array}{c}\text { Midday Average } \\
10^{6} \text { molec. } \text { cm }^{-3} \mathrm{~s}^{-1}\end{array}$ \\
\hline \multicolumn{3}{|l|}{ SOURCES } \\
\hline NMHC & 7.4 & 10.5 \\
\hline $\mathrm{CO}$ & 2.4 & 2.9 \\
\hline $\mathrm{CH}_{4}(1.842 \mathrm{ppmv})$ & 1.0 & 1.2 \\
\hline $\mathrm{HCHO}(3 \mathrm{ppbv})$ & 5.2 & 6.5 \\
\hline $\mathrm{H}_{2}+\mathrm{H}_{2} \mathrm{O}_{2}$ & 0.6 & 0.8 \\
\hline Total Sources & 16.5 & 22.0 \\
\hline \multicolumn{3}{|l|}{ SINKS } \\
\hline $\mathrm{HO}_{2}+\mathrm{NO}$ & -13.2 & -10.6 \\
\hline $\mathrm{HO}_{2}+\mathrm{RO}_{2}$ & -1.8 & -2.3 \\
\hline $\mathrm{HO}_{2}+\mathrm{HO}_{2}$ & -1.6 & -2.1 \\
\hline $\mathrm{HO}_{2}+\mathrm{O}_{3}$ & -0.9 & -1.3 \\
\hline $\mathrm{RO}_{2}+\mathrm{RO}_{2}$ & -0.1 & -0.2 \\
\hline $\mathrm{HO}_{2}+\mathrm{OH}$ & -0.2 & -0.3 \\
\hline Total Sinks & -17.8 & -16.7 \\
\hline
\end{tabular}

magnitudes of the source reactions are equal to those of the corresponding $\mathrm{OH}$ sinks discussed in the last section.

By far the most dominant sink for $\mathrm{RO}_{\mathrm{X}}$ was found to be the reaction of $\mathrm{RO}_{2}$ radicals with NO. As previously discussed, this was most pronounced during the conversion of $\mathrm{HO}_{2}$ to $\mathrm{OH}$ during the mid to late morning. By comparison, the relative importance of the other sink reactions was almost 

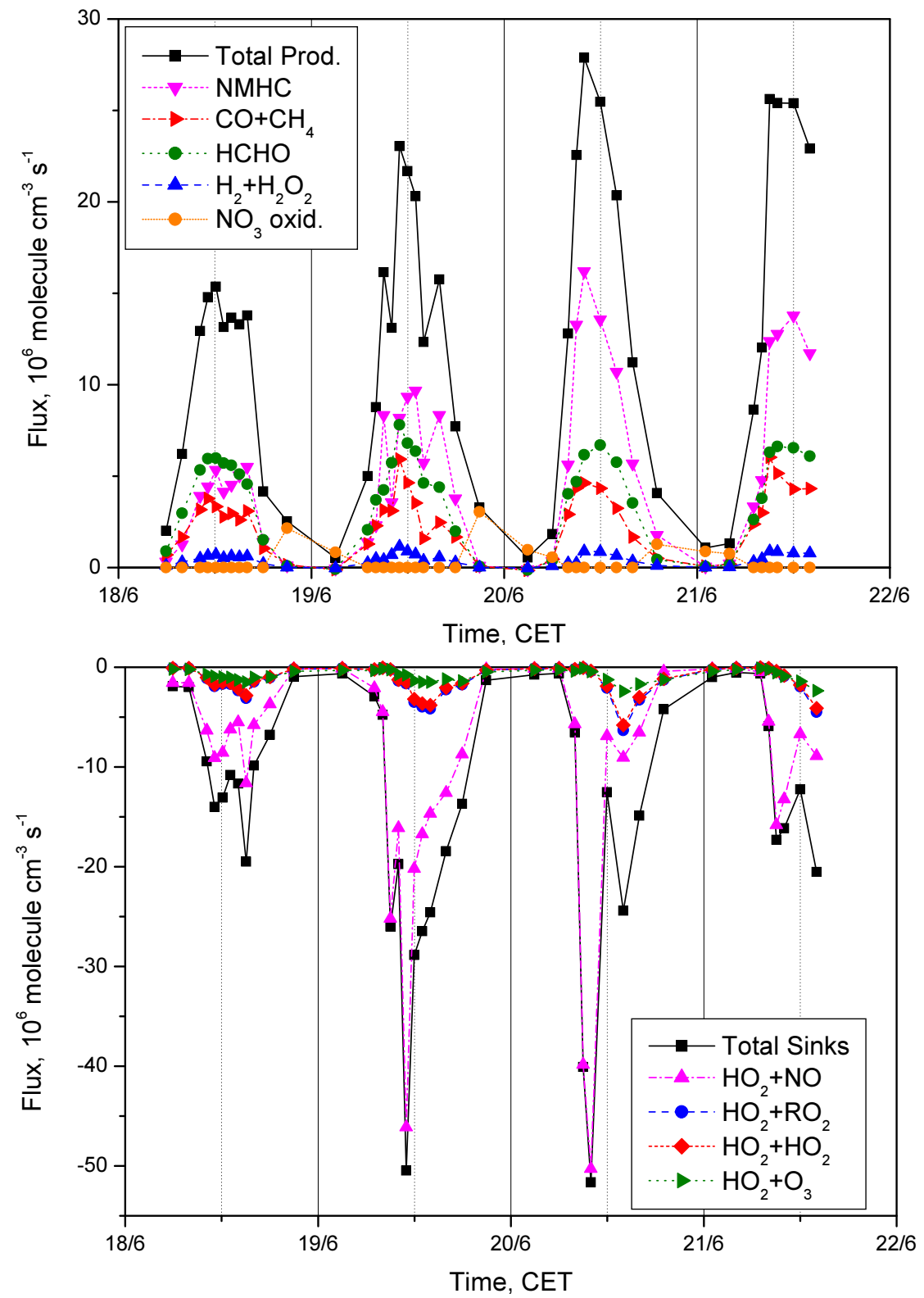

Fig. 10. Plot of the calculated contributions of various sources and sinks of $\mathrm{RO}_{\mathrm{X}}$ for the period $18-21$ June 2000 . The scales are different for the two panels. Sinks were calculated using the measured $\mathrm{RO}_{\mathrm{X}}$ mixing ratios.

negligible during these periods. The sink reaction of $\mathrm{NO}$ and $\mathrm{RO}_{2}$ causes a slower build up of $\mathrm{RO}_{\mathrm{X}}$ radicals relative to the diurnal increase of $\mathrm{OH}$ and radiation and a shift of the maximum $\mathrm{RO}_{\mathrm{X}}$ mixing ratio to mid afternoon.

Following the drop in the NO concentration around midday on all days except 19 June, reactions between peroxy radicals and the reaction of $\mathrm{HO}_{2}$ with $\mathrm{O}_{3}$ become more important, so that eventually more $\mathrm{RO}_{\mathrm{X}}$ radicals are lost due to these reactions than due to the loss reaction with NO. The self reaction of $\mathrm{HO}_{2}$, and the reactions between $\mathrm{HO}_{2}$ and $\mathrm{RO}_{2}$ (Reactions 13 and 14 in Table 2) are the dominant re- actions between peroxy radicals. In the base case scenario, $\mathrm{HO}_{2}$ and $\mathrm{RO}_{2}$ were assumed to be present in equal amounts, so that the respective turnover rates are similar in magnitude.

\subsection{Testing the model assumptions}

The effects of the various assumptions made in the model were also investigated. This was done by running the model for various scenarios with different assumptions about the composition and chemistry of the $\mathrm{RO}_{\mathrm{X}}$ radicals. The results for the different scenarios are shown in Fig. 11. Scenario I 


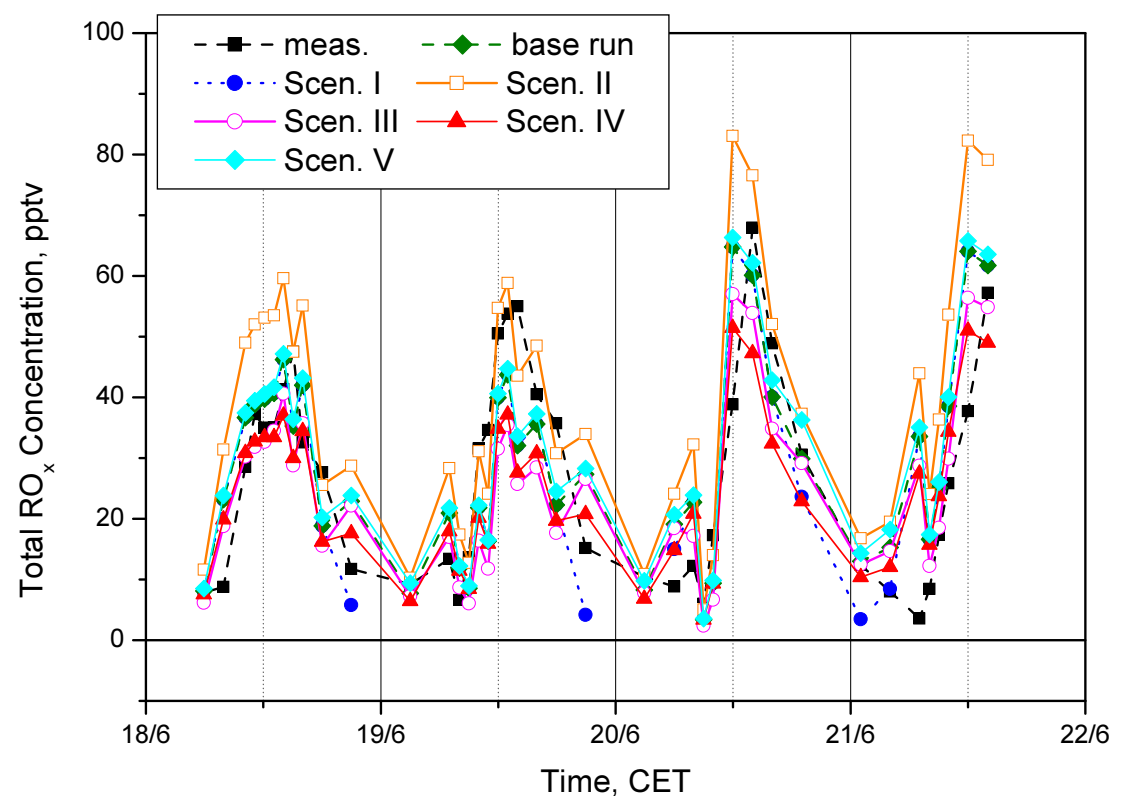

Fig. 11. Comparison of the $\mathrm{RO}_{\mathrm{x}}$ mixing ratios obtained using the photostationary state radical model for the following scenarios. The scenarios are discussed in the text.

$\begin{array}{ll}\text { Base Run } & \text { As in Fig. } 9 \text { with } \mathrm{HCHO} \text { and } \mathrm{NO}_{3} \text { oxidation } \\ \text { Scenario I } & \text { without } \mathrm{NO}_{3} \text { oxidation } \\ \text { Scenario II } & \text { with }\left[\mathrm{HO}_{2}\right]=\left[\mathrm{RO}_{2}\right] / 2 \\ \text { Scenario III } & \text { with only } 50 \% \text { conversion of } \mathrm{RO}_{2} \text { to } \mathrm{HO}_{2} \\ \text { Scenario IV } & \text { with reaction coefficients for } \mathrm{R} \geq \mathrm{C}_{2} \\ \text { Scenario V } & \text { with } 50 \% \text { yield of } \mathrm{RO}_{2} \text { from ozonolysis of alkenes }\end{array}$

ignored the production of $\mathrm{RO}_{2}$ via the nighttime oxidation of alkenes by the $\mathrm{NO}_{3}$ radical, and fails to produce the significant $\mathrm{RO}_{\mathrm{X}}$ levels measured at night. The $\mathrm{RO}_{\mathrm{X}}$ mixing ratios could not be calculated in two cases. This is a consequence of the occasionally slightly negative nighttime $\mathrm{OH}$ concentrations, which were nevertheless not significantly different from zero (see Sect. 3 and Fig. 2). Based on the $\mathrm{OH}$ detection limit of $4 \times 10^{5}$ molecules $\mathrm{cm}^{-3}$, the corresponding uncertainty in the calculated $\mathrm{RO}_{\mathrm{X}}$ mixing ratio was determined to be about 6 pptv. Thus, it is likely that the nighttime production of $\mathrm{RO}_{\mathrm{X}}$ by the $\mathrm{NO}_{3}$ radical cannot be ignored for the conditions prevailing during HOPE 2000. Although the nighttime $\mathrm{NO}_{3}$ levels have only been estimated, the results indicate that nighttime oxidation of alkenes via $\mathrm{NO}_{3}$ oxidation were most likely a substantial (probably even the dominant) source, of the observed nighttime $\mathrm{RO}_{\mathrm{X}}$ radicals.

In Scenario II, the assumption was made that, due to the high concentrations of biogenic terpenes, the concentration of $\mathrm{RO}_{2}$ was twice that of $\mathrm{HO}_{2}$. Measurements of this ratio during the BERLIOZ campaign by Platt et al. (2002) have shown that this ratio can vary considerably, both on a dayto-day basis and during the course of the same day. The assumption with respect to this ratio was found to have the largest impact on the calculated $\mathrm{RO}_{\mathrm{X}}$ mixing ratios compared to the other scenarios. This also demonstrates the limitations in the available data base and the need for further more detailed $\mathrm{RO}_{\mathrm{X}}$ and $\mathrm{HO}_{2}$ measurements.

$\mathrm{OH}$ concentrations calculated using scenario II are presented in Fig. 12. The results were systematically lower by an average of $30 \%$ than the base case scenario and were generally lower than or comparable to the corresponding measured data. Two exceptions occurred during daytime on 19 June, when the calculated $\mathrm{OH}$ concentrations exceeded measured concentrations by more than the uncertainty range for the measurements (39\%). Nevertheless, Scenario II resulted in an improved agreement between modelled and measured $\mathrm{OH}$ concentrations in most cases, with the exception of 21 June.

The assumption of equal partitioning between $\mathrm{HO}_{2}$ and $\mathrm{RO}_{2}$ used in the model is not justified for nighttime conditions since the $\mathrm{HO}_{2}$ radical is removed much more quickly from the atmosphere than $\mathrm{RO}_{2}$, due to the faster reaction of $\mathrm{HO}_{2}$ with other peroxy radicals. This removes a major sink for $\mathrm{RO}_{2}$ during the night. By assuming a 1:1 partitioning, the nighttime $\mathrm{RO}_{\mathrm{X}}$ mixing ratio may be slightly underestimated, although $\mathrm{NO}_{3}$ chemistry probably dominates the nighttime budget of $\mathrm{RO}_{\mathrm{X}}$. In contrast to the $\mathrm{RO}_{\mathrm{X}}$ concentrations, $\mathrm{OH}$ concentrations calculated on the basis of the assumption of 


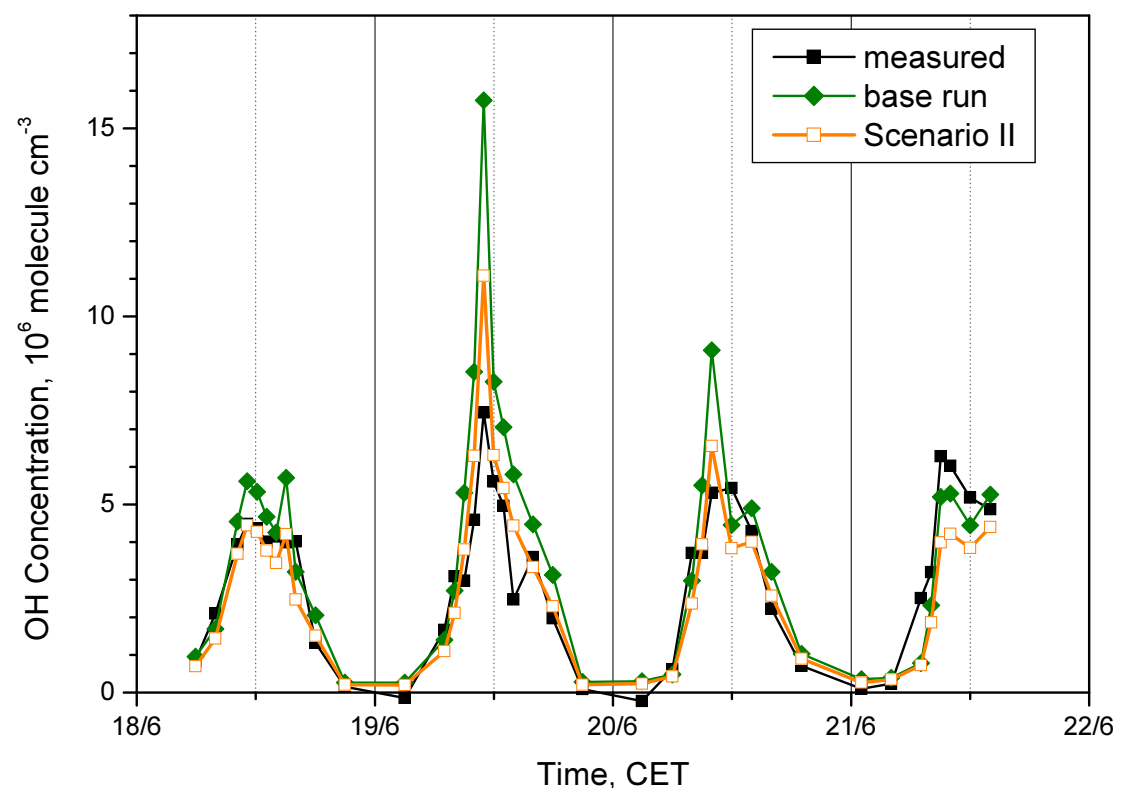

Fig. 12. Comparison of the $\mathrm{OH}$ concentration obtained using the photostationary state radical model for the base run and for Scenario II.

equal partitioning between $\mathrm{HO}_{2}$ and $\mathrm{RO}_{2}$ are overestimated. Since the dominant production of $\mathrm{OH}$ at nighttime proceeds via the reaction of $\mathrm{HO}_{2}$ with $\mathrm{NO}$ and $\mathrm{O}_{3}$, a reduction in the concentration of $\mathrm{HO}_{2}$ is directly linked to a reduction in the $\mathrm{OH}$ concentration. As a result, $\mathrm{OH}$ concentrations calculated using scenario 2 corresponded better to the measured concentrations at night.

The effect of a predominance of those $\mathrm{RO}_{2}$ species whose reactions differ substantially from those of the $\mathrm{CH}_{3} \mathrm{O}_{2}$ radical was investigated using Scenarios III-V. Scenario III assumed that the reaction of $\mathrm{RO}_{2}$ with $\mathrm{NO}$ (Reaction 10 in the introduction) and the subsequent Reaction 11 only resulted in a $50 \%$ net yield of $\mathrm{HO}_{2}$. A reduction in the $\mathrm{HO}_{2}$ yield can occur for longer chain peroxy radicals due to a higher yield of $\mathrm{RONO}_{2}$ via the reaction between $\mathrm{RO}_{2}$ and $\mathrm{NO}$, and for RO radicals which react relatively slowly, or not at all, with $\mathrm{O}_{2}$. In Scenario IV, reaction coefficients more typical of longer chain peroxy radicals were used for the $\mathrm{RO}_{2}$ reactions, instead of the corresponding $\mathrm{CH}_{3} \mathrm{O}_{2}$ reaction coefficients. Each of these scenarios resulted in an average reduction of the $\mathrm{RO}_{\mathrm{X}}$ concentrations by $10-20 \%$. In Scenario $\mathrm{V}$, the yield of $\mathrm{RO}_{\mathrm{X}}$ from alkene ozonolysis was assumed to be $50 \%$. The results from this scenario showed that this potential source of $\mathrm{RO}_{\mathrm{X}}$ contributed to an increase of less than $5 \%$ for daytime $\mathrm{RO}_{\mathrm{X}}$ mixing ratios. At night, alkene-ozone reactions potentially have a larger impact on $\mathrm{RO}_{\mathrm{X}}$ production, however, their role is estimated to be smaller than that of $\mathrm{NO}_{3}$-alkene reactions. This finding differs from the results of Salisbury et al. (2001), which was obtained at a site on the west coast of Ireland. However, they encountered substantially lower $\mathrm{NO}_{2}$ levels during their study, and correspondingly lower $\mathrm{NO}_{3}$ production rates.
Further calculations were made to examine the effect of the species not measured during HOPE 2000, e.g. HCHO and oxygenated hydrocarbons. A total of $63 \mathrm{NMHC}$ were measured during HOPE 2000, and these are thought to include most of the "pure" hydrocarbon compounds important for local photochemistry. However, other VOCs, especially the products and intermediates of the oxidation of hydrocarbons, also react rapidly with $\mathrm{OH}$. In other studies (e.g. Goldan et al., 1997), up to about $50 \%$ of the VOC oxidation rate was found to be due to further reactions of oxygenated compounds. Thus, to account for the contributions of potentially important VOC compounds not measured in the present study the NMHC oxidation rate was doubled in the calculations. This resulted in an increase in the calculated $\mathrm{RO}_{\mathrm{X}}$ mixing ratio of $50 \%$, and a reduction in the $\mathrm{OH}$ concentration by $30 \%$. Compared to the base case scenario, this assumption overpredicted $\mathrm{RO}_{\mathrm{X}}$ and underpredicted $\mathrm{OH}$ during most of the period considered here. Even in the base case scenario, oxidation products are already partly accounted for by assuming the presence of an HCHO proxy with a mixing ratio of $3 \mathrm{ppbv}$, so that doubling the NMHC turnover rate is an extreme assumption. A similar effect is achieved by increasing the assumed mixing ratio of $\mathrm{HCHO}$, although this results in an additional source of peroxy radicals due to the additional contribution of carbonyl photolysis.

\section{Conclusions}

The present measurements and model results demonstrate the potentially important role of $\mathrm{HO}_{\mathrm{X}}$ recycling in determining the temporal profiles of both $\mathrm{OH}$ and $\mathrm{RO}_{\mathrm{X}}$ at a rural 
background station such as Hohenpeissenberg. Using a relatively simple photostationary state radical balance model constrained by measured data, it was possible to reproduce the main features of the diurnal profiles of both these radicals during the measurement period of 18-21 June 2000 considered here.

$\mathrm{RO}_{\mathrm{X}}$ mixing ratios were observed to peak in the early afternoon. This is quite different to the maximum in the $\mathrm{OH}$ concentration which occurred during the late morning hours. This can be understood on the basis of the relative contributions of the dominant source and sink terms contributing to the $\mathrm{HO}_{\mathrm{x}}$ cycle calculated using the model. It was found that $\mathrm{RO}_{\mathrm{X}}$ accumulates over the course of the day as it is produced by $\mathrm{NMHC}$ oxidation, with maximum $\mathrm{RO}_{\mathrm{x}}$ production occurring at the time of the maximum $\mathrm{OH}$ concentration. The presence of elevated NO levels (as observed in the late morning hours) suppresses $\mathrm{RO}_{\mathrm{X}}$ levels due to their rapid reaction with $\mathrm{NO}$, which produces $\mathrm{NO}_{2}$. At the same time, this leads to rapid regeneration of $\mathrm{OH}$ and the observed peak concentrations of OH. During the HOPE 2000 campaign, the maximum mixing ratio of $\mathrm{NO}$ occurred during late morning and was associated with the transport of polluted air from the boundary layer.

Although the recycling of $\mathrm{OH} / \mathrm{HO}_{2}$ dominates both profiles, the $\mathrm{OH}$ concentration is also suppressed during the daylight hours due to its rapid reaction with NMHCs. The biogenic NMHCs, particularly isoprene, were present at quite high mixing ratios during the day, and were the main sink for the $\mathrm{OH}$ radical.

Under the conditions experienced during HOPE 2000, biogenic hydrocarbons were a major source of $\mathrm{RO}_{2}$. Therefore, it seems reasonable to conclude that longer chain $\mathrm{RO}_{2}$ may have made a significant contribution to the total $\mathrm{RO}_{\mathrm{X}}$ mixing ratios. This may have resulted in higher $\mathrm{RO}_{2} / \mathrm{HO}_{2}$ ratios than used for the base run due to the slower reaction of these long chain $\mathrm{RO}_{2}$ with other $\mathrm{RO}_{2}$ and a faster reaction with $\mathrm{HO}_{2}$. The yield of organic nitrates from the reaction with NO may also have been higher, slowing down the recycling of $\mathrm{RO}_{\mathrm{X}}$ to $\mathrm{OH}$. Thus, the conditions encountered during HOPE 2000 may be best approximated by a combination of scenarios II, III and V to describe the $\mathrm{RO}_{\mathrm{X}}$ chemistry. However, the combined effects of these scenarios were relatively small and partially compensated one another. Thus, the base case scenario should still describe the situation well.

A previous campaign also conducted in a similar rural and forested environment to HOPE 2000 was the PROPHET campaign. High mixing levels of biogenic hydrocarbons and low NO levels of 40-100 pptv were reported (Tan et al., 2001). The NO levels were comparable to the afternoon mixing ratios during HOPE 2000. The PROPHET calculations using the Regional Atmospheric Chemistry Model (RACM) resulted in $\mathrm{OH}$ concentrations which were a factor of 2.7 lower than the measured values. This discrepancy was largest at low NO levels. Although various factors of potential importance were considered by Tan et al. (2001), they could not adequately explain the large difference between modelled and measured $\mathrm{OH}$ concentrations.

Oxygenated NMHCs such as $\mathrm{HCHO}$ are an important group of trace gases which have a significant effect on the $\mathrm{OH}$ balance. The current study assumed the presence of $3 \mathrm{ppbv}$ $\mathrm{HCHO}$ as a proxy for oxygenated NMHCs, which resulted in a $20-30 \%$ increase in calculated $\mathrm{RO}_{\mathrm{X}}$ mixing ratios. While the assumption of 3 ppbv HCHO may be a good average approximation for summertime conditions, real mixing ratios may have varied significantly during the course of the HOPE 2000 campaign. The missing oxygenated NMHCs, especially HCHO, is a major deficit of HOPE 2000, and these compounds need to be taken into greater consideration in future campaigns.

Although a number of recent studies, including HOPE 2000 , have attempted to achieve closure of the $\mathrm{OH}$ and $\mathrm{RO}_{\mathrm{X}}$ budgets, the results show that this aim cannot currently be considered to have been achieved. In addition to the requirement of including additional components in the measurements, e.g. of aldehydes and ketones and potentially important photolysis frequencies in addition to $\mathrm{j}_{\mathrm{O}^{1} \mathrm{D}}$ and $\mathrm{j}_{\mathrm{NO}_{2}}$, the current study underlines the importance of constraining the $\mathrm{HO}_{2} / \mathrm{RO}_{2}$ partition ratio by $\mathrm{RO}_{\mathrm{X}}$ radical measurements in future studies.

Acknowledgements. The authors wish to thank T. Elste, K. Michl, G. Stange, R. T. Wilhelm and the staff of the Meteorological Observatory Hohenpeissenberg for their assistance during HOPE, and U. Schmidt of the Institute for Meteorology and Geophysics, Frankfurt am Main, for his support. The Peroxy Radical Chemical Amplifier was financed by the Hessische Landesamt für Umwelt und Geologie.

\section{References}

Abram, J., Creasey, D. J., Heard, D. E., Lee, J. D., and Pilling, M. J.: Hydroxyl radical and ozone measurements in England during the solar eclipse of 11 August 1999, Geophys. Res. Lett., 27, 34373440, 2000.

Ashbourn, S. F. M., Jenkin, M. E., and Clemitshaw, K. C.: Laboratory studies of the response of a peroxy radical chemical amplifier to $\mathrm{HO}_{2}$ and a series of organic peroxy radicals, J. Atmos. Chem., 29, 233-266, 1998.

Atkinson, R.: Gas-phase tropospheric chemistry of organic compounds, J. Phys. Chem. Ref. Data, Monograph 2, 1-216, 1994.

Atkinson, R.: Gas-phase tropospheric chemistry of Volatile Organic Compounds: 1. Alkanes and Alkenes, J. Phys. Chem. Ref. Data, 26, 215-290, 1997.

Atkinson, R.: Atmospheric chemistry of VOCs and $\mathrm{NO}_{\mathrm{x}}$, Atm. Environ., 34, 2063-2101, 2000.

Atkinson, R. and Aschmann, S.: OH radical reaction rate constants for polycyclic alkanes: Effects of ring strain and consequences for estimation methods, Int. J. Chem. Kinet., 22, 983-989, 1992.

Atkinson, R., Baulch, D. L., Cox, R. A., Hampson, Jr., R. F., Kerr, J. A., Rossi, M. J., and Troe, J.: Evaluated kinetic and photochemical data for atmospheric chemistry, organic species: Supplement VII, J. Phys. Chem. Ref. Data, 28, 191-393, 1999. 
Atkinson, R., Baulch, D. L., Cox, R. A., Crowley, J. N., Hampson, Jr., R. F., Kerr, J. A., Rossi, M. J., and Troe, J.: Summary of evaluated kinetic and photochemical data for atmospheric chemistry: IUPAC subcommittee on gas kinetic data evaluation for atmospheric chemistry, Web Version, http://www.iupac-kinetic. ch.cam.ac.uk/, 2001.

Benning, L. and Wahner, A.: Measurements of atmospheric formaldehyde $(\mathrm{HCHO})$ and acetaldehyde $\left(\mathrm{CH}_{3} \mathrm{CHO}\right)$ during POPCORN 1994 using 2.4-DNPH coated silica cartridges, J. Atmos. Chem., 31, 105-117, 1998.

Berresheim, H., Elste, T., Plass-Dülmer, C., Eisele, F. L., and Tanner, D.: Chemical ionization mass spectrometer for long-term measurements of atmospheric $\mathrm{OH}$ and $\mathrm{H}_{2} \mathrm{SO}_{4}$, Int. J. Mass Spectrom., 202, 91-103, 2000.

Cantrell, C. A., Stedman, D. H., and Wendel, G. J.: Measurement of atmospheric peroxy radicals by chemical amplification, Anal. Chem., 56, 1496-1502, 1984.

Cantrell, C. A., Shetter, R. E., Calvert, J. G., Parrish, D. D., Fehsenfeld, F. C., Goldan, P. D., Kuster, W., Williams, E. J., Westberg, H. H., Allwine, G., and Martin, R.: Peroxy radicals as measured in ROSE and estimated from photostationary state deviations, J. Geophys. Res., 98, 18 355-18366, 1993.

Cantrell, C. A., Shetter, R. E., Gilpin, T. M., and Calvert, J. G.: Peroxy radicals measured during Mauna Loa Observatory Photochemistry Experiment 2 - The data and first analysis, J. Geophys. Res., 101, 14 643-14 652, 1996.

Cantrell, C. A., Shetter, R. E., Calvert, J. G., Eisele, F. L., Williams, E., Baumann, K., Brune, W. H., Stevens, P. S., and Mather, J. H.: Peroxy radicals from photostationary state deviations and steady state calculations during the Tropospheric OH Photochemistry Experiment at Idaho Hill, Colorado, 1993, J. Geophys. Res., 102, 6369-6378, 1997a.

Cantrell, C. A., Zimmer, A., and Tyndall, G. S.: Absorption cross sections for water vapour from 183 to $193 \mathrm{~nm}$, Geophys. Res. Lett., 24, 2195-2198, 1997b.

Carroll, M. A., Bertman, S. B., and Shepson, P. B.: Overview of the Program for Research on Oxidants: PHotochemistry, Emissions, and Transport (PROPHET) summer 1998 measurements intensive, J. Geophys. Res., 106, 24 275-24 288, 2001.

Carslaw, N., Creasey, D. J., Heard, D. E., Lewis, A. C., McQuaid, J. B., Pilling, M. J., Monks, P. S., Bandy, B. J., and Penkett, S. A.: Modeling $\mathrm{OH}, \mathrm{HO}_{2}$, and $\mathrm{RO}_{2}$ radicals in the marine boundary layer - 1 . model construction and comparison with field measurements, J. Geophys. Res., 104, 30 241-30 255, 1999.

Carslaw, N., Creasey, D. J., Harrison, D., Heard, D. E., Hunter, M. C., Jacobs, P. J., Jenkin, M. E., Lee, J. D., Lewis, A. C., Pilling, M. J., Saunders, S. M., and Seakins, P. W.: $\mathrm{OH}$ and $\mathrm{HO}_{2}$ radical chemistry in a forested region of north-western Greece, Atm. Environ., 35, 4725-4737, 2001.

Carslaw, N., Creasey, D. J., Heard, D. E., Jacobs, P. J., Lee, J. D., Lewis, A. C., McQuaid, J. B., Pilling, M. J., Baguitte, S., Penkett, S. A., Monks, P. S., and Salisbury, G.: Eastern Atlantic Spring Experiment 1997 (EASE97) 2. Comparisons of model concentrations of $\mathrm{OH}, \mathrm{HO}_{2}$, and $\mathrm{RO}_{2}$ with measurements, J. Geophys. Res., 107, 10.1029/2001JD001 568, 2002.

Corchnoy, S. B. and Atkinson, R.: Kinetics of the gas-phase reactions of $\mathrm{OH}$ and $\mathrm{NO}_{3}$ radicals with 2-carene, 1,8-cineole, pcymene, and terpinolene, Environ. Sci. Technol., 24, 1497-1502, 1990.
Creasey, D. J., Heard, D. E., and Lee, J. D.: Eastern Atlantic Spring Experiment 1997 (EASE97) 1. Measurements of $\mathrm{OH}$ and $\mathrm{HO}_{2}$ concentrations at Mace Head, Ireland, J. Geophys. Res., 107, 10.1029/2001JD000 892, 2002.

George, L. A., Hard, T. M., and O'Brien, R. J.: Measurement of free radicals $\mathrm{OH}$ and $\mathrm{HO}_{2}$ in Los Angeles smog, J. Geophys. Res., 104, 11643-11 656, 1999.

Goldan, P. D., Kuster, W. C., Fehsenfeld, F. C., and Montzka, S. A.: Hydrocarbon measurements in the southeastern United States: The Rural Oxidants in the Southern Environment (ROSE) Program 1990, J. Geophys. Res., 100, 25 945-25 963, 1995.

Goldan, P. D., Kuster, W. C., and Fehsenfeld, F. C.: Nonmethane hydrocarbon measurements during the Tropospheric OH Photochemistry Experiment, J. Geophys. Res., 102, 6315-6324, 1997.

Guenther, A. B., Zimmerman, P., Harley, P., Monson, R., and Fall, R.: Isoprene and monoterpene emission rate variability: Model evaluation and sensitivity analysis, J. Geophys. Res., 98, 12 609$12617,1993$.

Handisides, G. M.: The Influence of Peroxy Radicals on Ozone Production, Dissertation, Johann-Wolfgang-Goethe University, Frankfurt am Main, http://diss.stub.uni-frankfurt.de/ cgi-bin-diss/show/meta?signatur=00000231, 2001.

Hastie, D. R., Weissenmayer, M., Burrows, J. P., and Harris, G. W.: Calibrated chemical amplifier for atmospheric $\mathrm{RO}_{\mathrm{X}}$ measurements, Anal. Chem., 63, 2048-2057, 1991.

Helmig, D., Greenberg, J., Guenther, A., Zimmerman, P., and Geron, C.: Volatile organic compounds and isoprene oxidation products at a temperate deciduous forest site, J. Geophys. Res., 103, 22 397-22 414, 1998.

Holland, F., Aschmutat, U., Heßling, M., Hofzumahaus, A., and Ehhalt, D. H.: Highly time resolved measurements of $\mathrm{OH}$ during POPCORN using Laser-Induced Fluorescence spectroscopy, J. Atmos. Chem., 31, 205-225, 1998.

Kanaya, Y., Sadanaga, Y., Hirokawa, J., Kajii, Y., and Akimoto, H.: Development of a ground-based LIF instrument for measuring $\mathrm{HO}_{\mathrm{X}}$ radicals: Instrumentation and calibrations, J. Atmos. Chem., 38, 73-110, 2001.

Kwok, E. and Atkinson, R.: Estimation of hydroxyl radical reaction rate constants for gas-phase organic compounds using a structure-reactivity relationship: An update, Atm. Environ., 29, 1685-1695, 1995.

Lamanna, M. S. and Goldstein, A. H.: In situ measurements of $\mathrm{C}_{2}-\mathrm{C}_{10}$ volatile organic compounds above a Sierra Nevada ponderosa pine plantation, J. Geophys. Res., 104, 21 247-21 262, 1999.

Mather, J. H., Stevens, P. S., and Brune, W. H.: $\mathrm{OH}$ and $\mathrm{HO}_{2}$ measurements using laser-induced fluorescence, J. Geophys. Res., 102, 6427-6436, 1997.

McKeen, S. A., Mount, G., Eisele, F., Williams, E., Harder, J., Goldan, P., Kuster, W., Liu, S. C., Baumann, K., Tanner, D., Fried, A., Sewell, S., Cantrell, C., and Shetter, R.: Photochemical modelling of hydroxyl and its relationship to other species during the Tropospheric OH Photochemistry Experiment, J. Geophys. Res., 102, 6467-6493, 1997.

Mihelcic, D., Volz-Thomas, A., Pätz, H. W., and Kley, D.: Numerical analysis of ESR spectra from atmospheric samples, J. Atmos. Chem., 11, 271-297, 1990.

Mihelcic, D., Klemp, D., Musgen, P., Patz, H., and Volz-Thomas, A.: Simultaneous measurements of peroxy and nitrate radicals at 
Schauinsland, J. Atmos. Chem., 16, 313-335, 1993.

Mihelcic, D., Konrad, S., Pätz, H.-W., Schmitz, T., Volz-Thomas, A., Holland, F., Hofzumahaus, A., Bächmann, H.-J. K., Geyer, A., and Perner, D.: Comparison of measurements of $\mathrm{OH}, \mathrm{HO}_{2}$ and $\mathrm{RO}_{2}$ radicals during the BERLIOZ campaign., presented at 8th IAMAS Scientific Assembly, Insbruck, Austria, 2001.

Mihele, C. M. and Hastie, D. R.: The sensitivity of the radical amplifier to ambient water vapour, Geophys. Res. Lett., 25, 19111913, 1998.

Mihele, C. M. and Hastie, D. R.: Optimized operation and calibration procedures for radical amplifier-type detectors, J. Atmos. Ocean Technol., 17, 788-794, 2000.

Mihele, C. M., Mozurkewich, M., and Hastie, D. R.: Radical loss in a chain reaction of $\mathrm{CO}$ and $\mathrm{NO}$ in the presence of water: Implications for the radical amplifier and atmospheric chemistry, Int. J. Chem. Kin., 31, 145-152, 1999.

Monks, P. S., Carpenter, L. J., Penkett, S. A., and Ayers, G. P.: Night-time peroxy radical chemistry in the remote boundary layer over the Southern Ocean, Geophys. Res. Lett., 23, 535538, 1996.

Montzka, S. A., Trainer, M., Angevine, W. M., and Fehsenfeld, F. C.: Measurements of 3-methyl furan, methyl vinyl ketone, and methacrolein at a rural forested site in the southeastern United States, J. Geophys. Res., 100, 11 393-11 401, 1995.

Mount, G. H., Brault, J. W., Johnston, P. V., Marovich, E., Jakoubek, R. O., Volpe, C. J., Harder, J., and Olson, J.: Measurement of tropospheric $\mathrm{OH}$ by long-path laser absorption at Fritz Peak Observatory, Colorado, during the OH Photochemistry Experiment, Fall 1993, J. Geophys. Res., 102, 6393-6413, 1997.

Novelli, P. C., Lang, P. M., Masarie, K. A., Hurst, D. F., Meyers, R., and Elkins, J. W.: Molecular hydrogen in the troposphere: Global distribution and budget, J. Geophys. Res., 104, $30427-$ 30 444, 1999.

Plass-Dülmer, C., Michl, K., Ruf, R., and Berresheim, H.: $\mathrm{C}_{2}$ $\mathrm{C}_{8}$ hydrocarbon measurement and quality control procedures at the Global Atmosphere Watch Observatory Hohenpeissenberg, J. Chromatogr. A, 953, 175-197, 2002.

Platt, U., Alicke, B., Dubois, R., Geyer, A., Hofzumahaus, A., Holland, F., Martinez, M., Mihelcic, D., Klüpfel, T., Lohrmann, B., Pätz, W., Perner, D., Rohrer, F., Schäfer, J., and Stutz, J.: Free radicals and fast photochemistry during BERLIOZ, J. Atmos. Chem., 42, 359-394, 2002.

Poppe, D., Zimmermann, J., Bauer, R., Brauers, T., Brüning, D., Callies, J., Dorn, H.-P., Hofzumahaus, A., Johnen, F.-J., Khedim, A., Koch, H., Koppmann, R., London, H., Müller, K., Neuroth, R., Plass-Dülmer, C., Platt, U., Rohrer, F., Röth, E.-P., Rudolph, J., Schmidt, U., Wallasch, M., and Ehhalt, D. H.: Comparison of measured $\mathrm{OH}$ concentrations with model calculations, J. Geophys. Res., 99, 16 633-16642, 1994.
Reichert, L.: Untersuchung des Wassereffektes eines Peroxyradikal-Detektors, M.S. Thesis, Institut für Umweltphysik, Universität Bremen, Bremen, 2000.

Reichert, L., Andrés Hernandez, M. D., Stöbener, D., Burket, J., and Burrows, J. P.: Investigation of the effect of water complexes in the determination of peroxy radical ambient concentrations: Implications for the atmosphere, J. Geophys. Res., 108, 4017, 10.1029/2002JD002 152, 2003.

Riemer, D., Milne, P. J., Farmer, C. T., and Zika, R.: Determination of terpene and related compounds in semi-urban air by GC-MSD, Chemosphere, 28, 837-850, 1994.

Ruggaber, A., Dlugi, R., and Nakajima, T.: Modelling of radiation quantities and photolysis frequencies in the troposphere, J. Atmos. Chem., 27, 171-210, 1994.

Salisbury, G., Rickard, A. R., Monks, P. S., Allan, B. J., Bauguitte, S., Penkett, S. A., Carslaw, N., Lewis, A. C., Creasey, D. J., Heard, D. E., Jacobs, P. J., and Lee, J. D.: Production of peroxy radicals at night via reactions of ozone and the nitrate radical in the marine boundary layer, J. Geophys. Res., 106, $12669-$ $12688,2001$.

Schultz, M., Heitlinger, M., Mihelcic, D., and Volz-Thomas, A.: Calibration source for peroxy radicals with built-in actinometry using $\mathrm{H}_{2} \mathrm{O}$ and $\mathrm{O}_{2}$ photolysis at $185 \mathrm{~nm}$, J. Geophys. Res., 100, 18 811-18 816, 1995.

Schwander, H., Koepke, P., Ruggaber, A., Nakajima, T., Kaifel, A., and Oppenrieder, A.: STARSci 2.1: System for Transfer of Atmospheric Radiation, http://www.meteo.physik.uni-muenchen. de/strahlung/uvrad/Star/STARinfo.htm, 2001.

Semadeni, M., Stocker, D., and Kerr, J.: The temperature dependence of the $\mathrm{OH}$ radical reactions with some aromatic compounds under simulated tropospheric conditions, Int. J. Chem. Kinet., 27, 287-304, 1995.

Solberg, S., Dye, C., Schmidbauer, N., Herzog, A., and Gehrig, R.: Carbonyls and nonmethane hydrocarbons at rural European sites from the Mediterranean to the Arctic, J. Atmos. Chem., 25, 3366, 1996.

Tan, D., Faloona, I., Simpas, J., Brune, W., Shepson, P., Couch, T., Summer, A., Carroll, M., Thornberry, T., Apel, E., Riemer, D., and Stockwell, W.: $\mathrm{HO}_{\mathrm{X}}$ budgets in a deciduous forest: Results from the PROPHET summer 1998 campaign, J. Geophys. Res., 106, 24 407-24 427, 2001.

Tanner, D. J., Jefferson, A., and Eisele, F. L.: Selected ion chemical ionization mass spectometric measurement of $\mathrm{OH}$, J. Geophys. Res., 102, 6415-6425, 1997.

Thompson, A. and Stewart, R.: Effects of chemical kinetics uncertainties on calculated constituents in a tropospheric photochemical model, J. Geophys. Res., 96, 13 089-13 108, 1991.

Umweltbundesamt: Jahresbericht 2000 des Messnetzes, Texte 77/01, Berlin, 2001. 